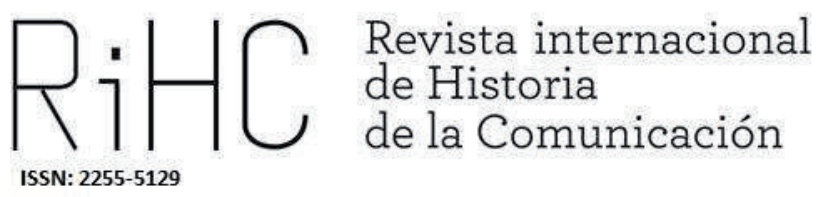

\title{
ESPAÑA CUMPLE 25 AÑOS DE PAZ, SUPLEMENTO NACIONAL DE LA PRENSA DEL MOVIMIENTO (1964). ENTRE LA PROPAGANDA Y LA DESAFECCIÓN (1 Y 2)
}

XXV Years of Spanish Peace, National Supplement of the Movement's Press (1964). Between the propaganda and the disafection (1 y 2)

DOI: http://dx.doi.org/10.12795/RiCH.2021.i16.18

Luis Arias González

Doctor en Historia

modestarias@hotmail.com

ORCID (D) 0000-0002-3749-9816

Francisco de Luis Martín

Universidad de Salamanca

deluis@usal.es

ORCID (D) 0000-0001-5233-2320

Como citar este artículo:

ARIAS, Luis y DE LUIS, Francisco (2021): “España cumple 25 años de Paz, suplemento nacional de la prensa del Movimiento (1964). Entre la propaganda y la desafección”, en Revista Internacional de Historia de la Comunicación, no 16, 2021, pp. 403-450. http://dx.doi.org/10.12795/RiCH.2021.i16.18 
Resumen: A través del análisis del Suplemento del 1 de abril de 1964, editado por la Prensa del Movimiento, se estudia el impacto de la campaña de propaganda institucional "XXV años de Paz Española" en los medios de comunicación y su distinta acogida e interpretación. Asimismo, sirve para reflejar las tensiones que existían entre las distintas familias del Régimen en aquel momento coyuntural y con respecto al proyecto conmemorativo dirigido por Fraga y su equipo. También, es una muestra del relevo generacional y la transformación del periodismo vivida en paralelo al acontecimiento.

Palabras clave: Fraga, 1964, propaganda, periodismo, franquismo.

Abstract: Through the analysis of the 1st April 1964 Supplement, published by the Movement's Press, the impact of the institutional propaganda campaign "XXV Years of Spanish Peace" on the media and its different reception and interpretation are studied. It also serves to reflect the tensions that existed between the different families of the Francoist regime at that time and with respect to the commemorative project led by Minister Fraga and his team. It is also an example of the generational change and the transformation of journalism experienced in parallel with the oficial conmemoration.

Keywords: Fraga, 1964, propaganda, journalism, francoism.

\section{1 "XXV años de Paz": encuadramiento y propuestas}

Se considera a 1964 una fecha emblemática en la historia del franquismo que marca, de forma precisa, "un antes y un después"; en esto, domina una rotunda -y sorprendente- unanimidad, por encima de las muy distintas interpretaciones historiográficas y doctrinales que se han vertido sobre la misma (Cañellas, 2009: 253280; Hispán, 2006; Molinero e Ysás, 2005; Sevillano, 1996; Townson, 2017, Zamarreño, 2015: 313-334). Ese año coincidió la efeméride de autoafirmación del Régimen, asentado de pleno en el interior y ya reconocido internacionalmente sin grandes problemas, con dos circunstancias ambientales totalmente novedosas; por una parte, la aceleración de un desarrollismo económico sin parangón que cristalizaría en el I Plan de Desarrollo (Torre, 2009: 61-88); por otra, la irrupción en la escena social y cultural de una generación inédita hasta entonces porque no había intervenido directamente en la Guerra Civil -elemento fundacional y clave del sistema- y que aportaba, además, una mentalidad diferente. El encaje de la celebración oficial de las bodas de plata de la Dictadura con estos dos poderosos condicionantes iría alterando las modestas y anquilosadas predicciones de partida del evento festivo, provocando una serie de consecuencias, tanto a corto como a medio plazo, que no fueron, precisamente, las previstas. 
En 1958, se creó una Comisión Ministerial presidida por el ministro de Información y Turismo Gabriel Arias Salgado, con el objeto de gestionar una celebración en la línea de lo que se había venido haciendo hasta entonces, para conmemorar los 25 años del 18 de julio con una única exposición:

Próximo a cumplirse el XXV aniversario del Alzamiento Nacional [...] parece ocasión propicia para poner de manifiesto cuanto el esfuerzo inquebrantable y ferviente del pueblo español, salvando con ilusionado espíritu de servicio dificultades y obstáculos, ha logrado en este periodo en el camino de la reconstrucción y engrandecimiento de la patria.

Por ello, se ha estimado oportuno que, coincidiendo con dicho aniversario, se celebre una Exposición Nacional en la que se recojan, bajo todos sus aspectos, las realizaciones y manifestaciones de la vida española en este cuarto de siglo.

El evento tenía como lema "Veinticinco años de vida española (1936-1961)" (Temas Españoles, 1961). Sufrió un retraso motivado por la generalizada contención del gasto público que precedió de manera inmediata al Plan de Estabilización (Torre, 2009: 6188), quedando fijada la fecha definitiva para 1964. Sin embargo, la versión oficial justificó la demora aduciendo un cambio en la efeméride que pasaba a ser la del día de la victoria, 1 de abril de 1939. Aun así, se mantenían el tono contenido de la propuesta inicial. Fue designado comisario el teniente general José María López Valencia ${ }^{1}$ y la comisión que presidía la integraban cuadros ministeriales junto a directores de Ferias de Muestras, casi todos ellos muy por encima de los 55 años.

La comisión apenas funcionaría hasta que la sustitución de Arias Salgado por Manuel Fraga como ministro de Información y Turismo, el 10 de julio de 1962, cambió radicalmente las cosas. A los dos meses de su nombramiento, Fraga pondría en pie un proyecto totalmente alejado del original y de dimensiones colosales, (Fraga, 1980). Nombró otra comisión, la "Junta Interministerial Conmemoradora [sic]", abierta ahora a todo el gabinete para dejar bien clara la intención totalizadora y apostó por una composición multitudinaria, presidida por él, aunque reservándose los cargos decisorios para los más afines: Pío Cabanillas como vicepresidente y su cuñado Carlos Robles Piquer como secretario. Operativamente, funcionaron tres comisarías y trece subcomisarías, destacando la de Actos Públicos -presidida por José Mạ. López de Valencia- y la de Publicaciones -José Mạ. Hernández Sampelayo-. Quienes en realidad marcaron las líneas fundamentales fueron una serie de altos técnicos de la Administración, de la misma -o cercana- generación que el ministro, con quien, en muchos casos, habían coincidido previamente en anteriores destinos. Este núcleo institucional contó con la presencia permanente de la entidad privada publicitaria más

\footnotetext{
${ }^{1}$ Premio a su actuación como Jefe del mando unificado en el conflicto de Sidi Ifni y un reconocimiento a la fama que tenía como militar de letras (Pacho, 2006: 109).
} 
adelantada de la época, el conjunto de empresas RED, S.A., fundadas por un jovencísimo Alfonso de Zunzunegui Redonet (Ybarra, 2013: 101-106) -entonces tenía 33 años-, a la que se le daría carta blanca.

Como sostienen los principales analistas y estudiosos de esta celebración (Aguilar, 2008; Marzo, 2009; Morán, 2014: 218-298), los "XXV años de Paz" supusieron una "campaña de propaganda sin precedentes", una "exaltación de los logros del franquismo" y un "culto a la personalidad del Caudillo", aunque su imagen hubiera ido cambiando con respecto a la de la larga posguerra, volviéndose menos bélica y menos heroica, más paternalista y desideologizada (Sánchez-Biosca, 2014; Ellwood, 1987: 225-238). Esto no supone que deba considerarse como un hecho histórico exclusivo de las dictaduras autoritarias ${ }^{2}$ y $\sin$ otros paralelismos. En el marco de la Guerra Fría y del desarrollismo occidental, tales montajes propagandísticos institucionales, de exaltación nacional y de los logros económico-sociales, fueron habituales. La celebración pionera del Festival of Britain -1951-, promovida por los laboristas (Conekin, 2003), devino en un modelo que serviría de inspiración a muchas otras como, por ejemplo, las bodas de plata de la reina Juliana en Holanda -1962-. En Francia, las teorías de Malraux en torno al intervencionismo cultural del Estado y al consumo cultural colectivo fueron profusamente aplicadas cuando llegó al Ministerio de Cultura en 1959; el modelo malrauxiano provocaría una gran admiración en toda Europa y toda una serie de adaptaciones encubiertas (Négrier, 2003: 3 y ss.).

Volviendo a las tres afirmaciones anteriores, debemos completarlas con las demás motivaciones que también estuvieron presentes en los "XXV años", aunque lo fueran en un grado menor, de forma oculta y hasta contradictoria. Una sería la propuesta tácita y tímida- de aprovechar el momento para llegar a una concordia nacional que superara la división entre vencedores y vencidos ${ }^{3}$; la otra, la pretensión de legitimar el Régimen por su actuación, en vez de por su origen, vinculándolo al proceso de modernización económica, social, cultural y artística que se estaba poniendo en marcha. Dos propuestas que ni el aparato estatal en su conjunto, ni las familias del Régimen, aceptarían con el mismo grado de entusiasmo.

La celebración de la Paz, concebida como un único gran acto pero de ocho meses de duración, estuvo integrada por una multitud de elementos que ocupaban cada uno de

\footnotetext{
${ }^{2}$ En Portugal, Joaquim Tavares Ferro, propagandista del salazarismo, dirigió la magna Exposiçâo do Mundo Português, con evidentes resabios de la escenografía fascista, aunque con una concepción muy vanguardista para el lugar y la época -1940- (Portela, 1987: 63-105).

${ }^{3}$ El gesto que la acompañaba, el "indulto general” por los XXV años de Paz Española, extinguía las penas accesorias, aún en vigor, por "el delito de rebelión" y eliminaba los antecedentes del Registro Central de Penados y Rebeldes.
} 
los días ${ }^{4}$, con la suficiente capacidad de penetración como para llegar a todos los rincones geográficos y a todas las capas de la población, independientemente de su nivel formativo y de sus gustos. En términos generales, la carga propagandística fluía encauzada en dos niveles, cada uno con sus correspondientes usuarios y sus medios propios de difusión, aunque estableciéndose espacios de contacto y actividades comunes entre ambos. El nivel superior, al que podríamos denominar también como "conceptual" u "oficialista", iba destinado fundamentalmente al consumo de los elementos rectores del Estado; comprendía las publicaciones técnicas (Publicaciones Españolas, 1964; Servicio Informativo Español, 1964a y 1964b) y toda la demás producción escrita con pretensiones elitistas o académicas (Publicaciones Españolas, 1964), así como las manifestaciones públicas de corte más tradicional y continuista ${ }^{5}$; también comprendía la actuación internacional llevada a cabo fuera de las fronteras ${ }^{6}$.

En cuanto al nivel inferior -el de "la nueva imagen"- iba enfocado al público en general y primaba una propaganda en donde lo formal era tan importante -o más- que el propio mensaje, con un sistema de captación basado en el espectáculo y el entretenimiento. Desde luego, esta modalidad sería la más sorprendente en todos los sentidos, con logros inauditos como el millón de visitantes que marcó la exposición de España 64, la tirada, también millonaria, del folleto España para usted de Máximo, que rompió con todos los moldes del género publicitario y la serie de carteles alusivos, empezando por el magnífico cartel oficial de Julián Santamaría reproducido en todo tipo de formatos y tan moderno en su concepción y colorido -incluía versiones en gallego, catalán y euskera- y continuando con las series de 150 carteles, España hoy: viva la Paz (Carredano, 1964), que se imprimieron con profusión (Díaz del Campo, 2017: 205-226) y que fueron encargados a lo más representativo y vanguardista del diseño de aquellos momentos (Núñez, 2006). Otro de sus hitos más populares sería la conocida película de Sáenz de Heredia, Franco ese hombre, y la menos conocida Sinfonía española producida por Samuel Bronston (García de Dueñas, 2000: 256-267), dirigida por Jaime Prades y con música de Halfter?.

\footnotetext{
${ }^{4}$ El chiste apócrifo -como tantos otros- atribuido a La Codorniz, en el que se veía un científico en un laboratorio con el lema equívoco, si se leía deprisa, de "XXV años de paz. Ciencia española", ejemplifica el hastío que llegó a generar la campaña.

${ }^{5}$ El inicio oficial de la celebración fue con un Te Deum en el Valle de los Caídos el día 1 de abril y el final con la colocación de la primera piedra del Palacio -"De la Paz"- de Congresos y Exposiciones de Madrid, el 21 de diciembre.

${ }^{6}$ Aparte de los actos en embajadas y consulados, la principal intervención fue la del Pabellón de la Paz en la feria internacional de Nueva York, diseñado por Javier Carvajal y que acogió obras de Vaquero Turcios, Pablo Serrano, Oteiza, Picasso, Gris y Miró.

${ }^{7}$ Halfter sería también uno de los tres músicos, junto a Luis de Pablo y Miguel Alonso, a los que se le encargó una obra específica en lo que fue el evento más arriesgado e incomprendido, el "Concierto de la Paz" del 16 de junio de 1964 (Contreras, 2016).
} 
Los medios de comunicación quedaban incorporados obligatoriamente al proyecto desde un principio, lo quisieran o no. Tenían que servir de vehículo de la campaña, a la vez que se les exigía la propagación de las consignas oficiales asociadas a la misma. Esto resultaba muy fácil de llevar a cabo en la incipiente televisión (Bustamante, 2013: 36-40), con una cadena única y una difusión muy reducida, bajo la dirección de Jesús Aparicio Bernal, tan identificado con los esquemas de Fraga ${ }^{8}$; y lo mismo sucedería con los reportajes del NO-DO, el escaparate ministerial "al alcance de todos" (SánchezBiosca, 2014: 192). La radio, como se sabe, era el medio de masas por excelencia (García, 1980), dada su extensión y aceptación social. A pesar del predominio de Radio Nacional de España, teóricamente no había monopolio puesto que se concedieron licencias para las radios comarcales a la SER, a Radio España y a Radio Intercontinental -propiedad de Serrano Suñer-. En cuanto a las emisoras locales -450-, estaban repartidas entre la confesional COPE y las pertenecientes a la Secretaría General del Movimiento: REM -Red de Emisoras del Movimiento-, y CES -Cadena de Emisoras Sindicales-. Todos estos medios guardaron plena sintonía con las directrices del Ministerio de Información y Turismo, teniendo en cuenta, además, que su campo de autonomía informativa era mínimo al seguir sujetos a la censura previa y estar obligados a conectar con RNE durante los boletines oficiales de noticias.

En la prensa, sin embargo, las posibilidades de interpretación y demostración de los diversos grados de adhesión, aún dentro de los estrechos márgenes permitidos, fueron mayores. Lo cual unido a su variedad y a la superior capacidad a la hora de transmitir y generar opinión, le confiere un valor añadido (Yanes, 1995: 71-79). De esto eran conscientes los directivos y periodistas del momento (Fernández Areal, 1971; González Seara, 1968; Instituto de la Opinión Pública, 1964) y así lo han demostrado los especialistas de la historia de la comunicación (Barrera, 1995; Chuliá, 2001; Fuentes y Fernández Sebastián, 1998; García Galindo, Gutiérrez Lozano y Sánchez Alarcón, 2002; López Pintor, 1982; Molinero e Ysás, 2005; Pizarroso, 1989; Sánchez Rada, 1996; Sevillano, 1996; Terrón, 1981). En esta línea de investigación, la Prensa del Movimiento ocupa por sí sola un importante apartado y cuenta con estudios muy completos sobre su conjunto (Zalbidea, 1996 y 2002) o sobre determinadas zonas o cabeceras periodísticas (Langa, 1998; Martín de la Guardia, 1994). Entonces, ¿qué sentido tiene este trabajo y qué aporta?

Al tomar como punto de partida un enfoque metodológico de carácter "micro", basado en un único número -el especial que la Prensa del Movimiento dedicó a los XXV años de Paz-, al que consideramos un paradigma múltiple (político-ideológico y periodístico-profesional), nos posibilita una aproximación sobre el grado de identificación -o de rechazo- de este grupo editorial estatal con la propuesta específica

\footnotetext{
${ }^{8}$ La inauguración de los estudios de Prado del Rey, el día 18 de julio, tuvo lugar en el marco de las celebraciones y contó con la presencia de Franco.
} 
del tándem Fraga-Robles sobre la celebración, así como la constatación de la existencia -o no- de una línea de pensamiento propia y común sobre este tema y sobre la influencia gubernamental ejercida en la opinión pública. Una fórmula de aproximación realizada a través del análisis de la estructura formal y estética del suplemento, que extendemos a los periodistas y a los demás colaboradores participantes, así como a los contenidos de sus páginas. Este análisis se completa con una comparación contrastada a través de una muestra significativa de medios escritos de la época de carácter nacional y de un ejemplo regional, Asturias.

\section{España cumple 25 años de Paz. Suplemento Nacional de la Prensa del Movimiento.}

\subsection{Los periódicos en 1964}

En 1964 la prensa española pasaba por un momento crítico agudizado con la intervención gubernamental a través del Ministerio de Información y Turismo. Mientras estaba teniendo lugar un cambio de ciclo vinculado a la renovación conceptual, tecnológica, estética y profesional, coexistían los antiguos esquemas de organización y de control informativo, arrastrados desde una, cada vez más lejana, posguerra (Diego, 2016). Seguía siendo primordial la división que marcaba la propiedad de los medios en dos grupos, cada vez más distantes y distintos: el sector público, con el 31'7\% del total, integrado por la Prensa del Movimiento (Heras, 2000) y por la Prensa Sindical (Amaya, 2008) y el sector privado que ya controlaba el 68'3\% de las tiradas. Entre los dos sacaban a la calle 107 diarios (Beneyto, 1965: 9-26). La media anual de ejemplares editados alcanzaba en esta fecha los 2.215.000, lo que suponía una cifra media de 71'3 periódicos por cada 1.000 habitantes, muy por debajo de la media europea (Aguado, 1996). Persistía, también, un control absoluto por parte del poder que iba desde el nombramiento de los directores hasta el detalle del precio de los periódicos; continuaban la tutela del sistema de acceso al carnet periodístico, la censura previa y la inserción obligatoria de consignas oficiales. Aun con todas esas trabas, podría hablarse de un cierto pluralismo latente, aunque fuera atenuado e incapaz de traspasar las líneas marcadas en este panorama que ha sido definido como "gubernamental pero no uniforme" (Beneyto, 1965: 23). 
Fraga consideraba que la modernización del sector de la comunicación estaba en relación directa con cualquier posible plan de modernización estatal y civil (Fraga, 1980: 54 y ss.). Con este proyecto puesto en práctica con las decisivas aportaciones de su equipo -el director de prensa, Manuel Jiménez Quiles, su subsecretario de confianza, Pío Cabanillas, y Juan Beneyto (Equiza, 2015)-, se pretendía conseguir una mayor confianza de la población con respecto a sus dirigentes y aumentar a la vez la presencia mediática de España en el exterior. La carga propagandística incidía en la puesta en marcha de una evolución cultural y política del Régimen en consonancia con el nuevo desarrollismo triunfante; "lo posible en nuestro tiempo", según las propias palabras del activo ministro, que llegaría a tocar techo con la Ley de Prensa e Imprenta de 1966 (Davara, 2005), que concitó en todos -incluido el propio Fraga- más ilusiones que verdaderos logros, en un gesto que pretendía enterrar para siempre la noción, indefendible ya en plenos años sesenta, de una "prensa orientada", según el lema de su predecesor ministerial. Pero, hasta llegar aquí, tuvieron que darse una serie de pasos preparatorios (Vela, 2009: 620-627), a la vez que se dotaba de verdaderas funciones profesionales y decisorias al Consejo Nacional de Prensa (Beneyto, 1986: 221 y ss.), el ente que había creado Arias Salgado en 1957 con una intención muy distinta, únicamente representativa y formalista.

Dentro de estos antecedentes previos, deben incluirse dos organismos que ejercieron como símbolos de cambio: el Club Internacional de Prensa, aparecido en 1962 y concebido como un lugar abierto de encuentro y discusión, y el Instituto de la Opinión Pública, surgido en 1963 bajo la dirección del jovencísimo jefe de la secretaría particular de Fraga, Luis González Seara (Alcobendas, 2006: 90), con la pretensión de servir de observatorio imparcial y como herramienta técnica de recogida de datos. A estos dos nuevos ámbitos se sumaría la promulgación del Estatuto de la Profesión Periodística del 6 de mayo de 1964, completado a su vez con el Estatuto de la Publicidad del 11 de junio de 1964 y con la Oficina de Justificación de la Difusión -20 octubre de 1964- (Aguado, 1996: 80). De la mano de este paquete de medidas legales y estructurales, se adoptaron otros estudiados gestos aperturistas de cara a la galería 9 . Uno de los más notorios fue el plácet concedido a cuatro nuevos periódicos locales y a tres revistas de talante crítico, casi contestatario, que marcarían el posfranquismo hasta convertirse en iconos opositores: Revista de Occidente -resurrecta en abril de 1963-, Cuadernos para el Diálogo, de Ruiz-Giménez -octubre de 1963- (Pando, 2009) y Triunfo -transformada en revista de información general en junio de 1962-, dirigida por José-Ángel Ezcurra (Castro, 2017: 99-116).

La Delegación Nacional de Prensa, Propaganda y Radio del Movimiento, en su sector de Prensa, padecía desde los años 50 un creciente temor a la decadencia y la pérdida

\footnotetext{
${ }^{9}$ Entre otros, la relajación en la emisión de consignas oficiales y el fin de la censura militar en lo relativo a los temas relacionados con la Guerra Civil.
} 
de hegemonía comunicacional; si bien, disfrutaba aún de una situación inmejorable, uno de sus "mejores momentos" (Heras, 2000: 41) según confirman las cifras absolutas y relativas correspondientes a 1964 (Instituto de Opinión Pública, 1964). Ese año, bajo su amparo, se editaron una media de 479.723 ejemplares al día, se alcanzó la captación máxima de lectores y hasta un sorprendente superávit económico en el que tenía mucho que ver la exención tributaria, vigente hasta 1968 (López Gallegos, 2003: 159-185). El emporio estatal contaba por entonces con 205 publicaciones entre periódicos -en torno a 1 de cada 5 del total nacional- y revistas, disponía de una agencia de información propia -PYRESA-, con diarios en todas las provincias de España -excepto Toledo-, y en algunas de ellas sacaba a la calle más de una cabecera, conservando la categoría de monopolio provincial en Alicante, Almería, Castellón, Córdoba, Cuenca, Gerona, Jaén y Tarragona. Unos años antes, en 1956, se habían puesto las bases de una reorganización estructural de la Prensa del Movimiento; y hasta hubo -en 1963-, un fallido intento de captación de capital privado encomendada a Garrigues Walker. Sin embargo, cundía el pesimismo y la sensación de no poder competir contra los triunfantes $A B C, Y a$, La Vanguardia o El Alcázar.

Al frente de la institución, se encontraba desde 1961 José María del Moral, sin una vinculación profesional exclusiva con el mundo de la información y con una dilatada carrera en el Consejo Nacional del Movimiento; nunca se mostró favorable a efectuar replanteamientos a gran escala, limitándose a un continuismo con ciertas concesiones a medidas menores de agilización administrativa y de modernización formal de los medios.

En tal ambiente, el matutino Arriba, considerado el buque insignia de la Delegación, con distribución por toda España, mantenía aun la aureola de representar el pensamiento oficial ortodoxo de la Dictadura (Estévez, 1977: 21), zafándose de la obligatoria censura previa. En 1961 había estrenado una flamante redacción en el paseo de la Castellana que sustituía a la de la calle Larra; allí, se llevaron también los talleres y la imprenta dotados con los mayores adelantos técnicos del momento. Todo ello resultó posible gracias a la eficaz dirección -1960-1962- de Rodrigo Royo Masía, que compatibilizaba su falangismo radical con la adopción de cuantas novedades técnicas iban surgiendo (Rodríguez Jiménez, 1994: 129-133). Sería él quien echase a andar el Arriba Dominical, un suplemento de los mejores de la época en cuanto a composición y atractivo estético. Su postura totalmente contraria a los pactos con los Estados Unidos motivó su destitución y posterior sustitución por parte de Sabino Alonso Fueyo (1962-1966), un reconocido intelectual orgánico, aunque sin la talla profesional que alcanzarían luego sus sucesores Manuel Blanco Tobío (1966-1970) o Jaime Capmany (1970-1971). Alonso Fueyo, falangista de primera hora y profesor universitario de filosofía en Valencia, tenía experiencia como director del diario Levante (1953-1962) y venía avalado por los premios oficiales José Antonio (1947), Jaime Balmes (1962) y Francisco Franco (1965), además de ser miembro del influyente 
Instituto de Estudios Políticos que actuaba de vivero para la provisión de los altos cargos del Movimiento. Su afinidad personal con Fraga no era compartida por muchos de los componentes de la redacción del Arriba, a pesar de su origen "azul y la animadversión común contra el sector tecnócrata del Gobierno cada vez más aupado sobre sus triunfos desarrollistas; esto generaría una relación fluctuante y contradictoria que, como veremos, aflorará con frecuencia en el número dedicado a los XXV años de Paz.

\subsection{Forma y fondo del Suplemento Nacional. Textos y autores.}

El Suplemento especial del miércoles 1 de abril de 1964 se adjuntaba de forma obligatoria con el periódico Arriba, y con todos los demás diarios de la cadena de Prensa del Movimiento, al precio unitario de 5 pesetas. Contaba con 164 páginas, en su tamaño habitual de DIN A3, más la portada y la contraportada, las únicas que iban impresas a color. De hecho, el conjunto de imágenes -fotografías, ilustraciones o gráficos-, suponía uno de los elementos fundamentales de la publicación, ocupando más del $65 \%$ de la superficie editada. Además, y sorprendentemente tratándose de un medio público (Heras, 2000), la publicidad estaba presente en 62 de las páginas -un 39\%-. (Vid. Fig.1).

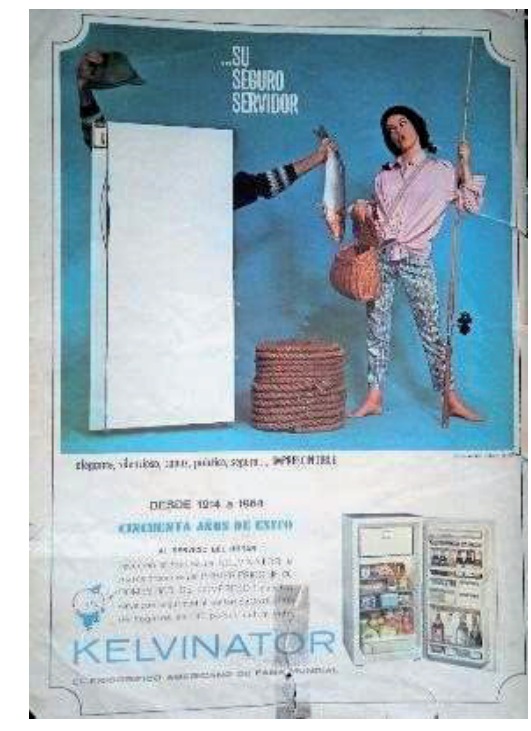

Figura 1. Ejemplo de publicidad (vuelta de portada).

Al revisar las firmas comerciales de los anuncios vemos que algo más de la mitad de las empresas pertenecían al INI o tenían vinculación estatal de algún tipo, como sucede con Ediciones de Cultura Hispánica, el Banco Exterior de España o Tabacalera. La contraportada (Vid. Fig.2) suponía todo un guiño cómplice al proceso de modernización puesto en marcha en la España de los 60, identificado con el soñado 
automóvil a través de los dos modelos estrellas de la motorización: el popular 600 y el recién aparecido en el mercado, el lujoso 1500, junto al lema de "Más del 50\% de los turismos que ruedan en España son Seat".

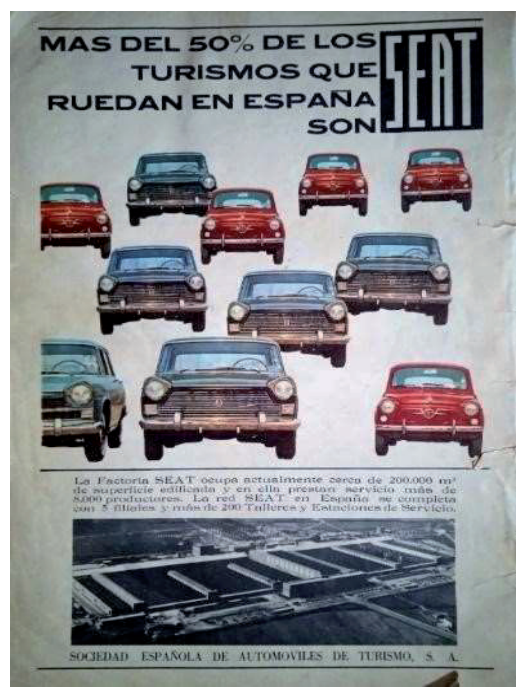

Figura 2. Contraportada.

La implantación de las empresas anunciadas era mayoritariamente nacional, perteneciendo a los sectores de la gran industria, la energía, el transporte y la banca. Junto a los reclamos publicitarios, encontramos también textos patrocinados por las firmas comerciales, que aprovechaban para relacionar así sus empresas con la paz española y con los planes desarrollistas del momento.

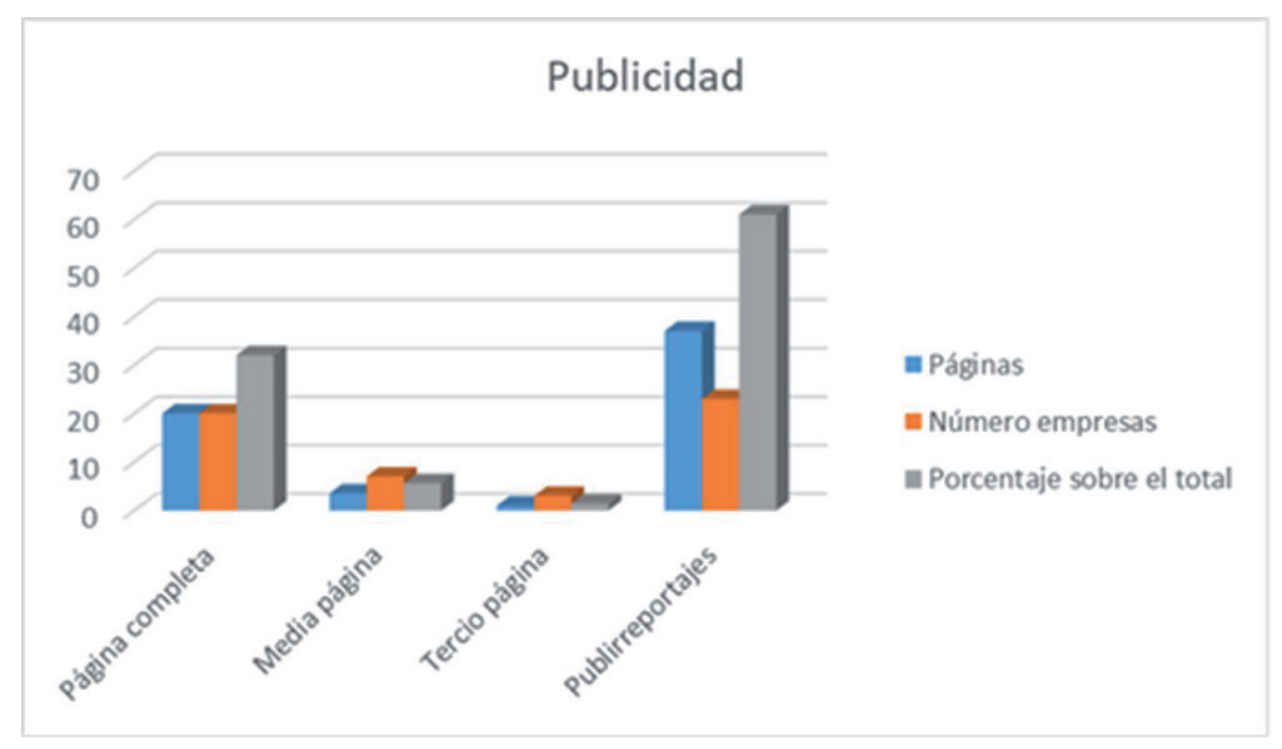

Gráfico 1. Distribución de la publicidad en el Suplemento Nacional.

La dirección y realización del número estuvo a cargo de José Antonio Revilla y Aguirre considerado como un reputado profesional a sus 44 años, por encima de su asumida filiación falangista contestataria, iniciada tempranamente en el SEU; esta postura le 
llevaría a involucrarse en los "Círculos Doctrinales José Antonio" (Márquez, 1977) desde la fundación de los mismos en 1959, llegando a hacerse cargo, en 1963, de su polémico boletín -Es así-, que acabaría siendo clausurado por orden gubernativa, al año siguiente (Márquez, 1977: 8). En dicha publicación de cariz disidente, coincidiría con Rodrigo Royo, su jefe directo en el Arriba. Royo, junto al economista Juan Velarde -otro gran dinamizador de los "Círculos"-, serían los principales valedores de su carrera periodística en el sector público. Paradójicamente, ni sus críticas al capitalismo doctrinario, ni sus acusaciones públicas sobre el desviacionismo de la doctrina joseantoniana por parte del Movimiento Nacional (Ruiz Carnicer, 2014: 80, Morales, 2007), le impidieron ser nombrado, en diciembre de 1961, Promotor central de Publicidad en la Prensa del Movimiento (Heras, 2000: 133); y no sólo eso, en diciembre de 1965 recibió el premio nacional de periodismo Francisco Franco por el tema “España en desarrollo 1965". Incluso, llegó a dirigir el semanario de economía Desarrollo, de titularidad propia compartida con José Juan Cebrián, al que convirtió en uno de los de mayor tirada en su género (Zabalza, 1966: 21) y en el que permaneció hasta su cierre, defendiendo -en total contradicción con sus creencias más íntimasproyectos como el Plan de Estabilización de 1959 y el Primer Plan de Desarrollo de 1964.

Revilla contó con la asistencia de dos técnicos de la casa para ayudarle en la confección material del montaje de la totalidad del número; fueron José Luis Herrero Tejedor hermano de Fernando Herrero Tejedor, entonces Vicesecretario General del Movimiento- y Pablo Martínez-Palomero. Ninguno resultaría decisivo a la hora de planificar la estructura temática y definir las líneas generales ideológicas del Suplemento, responsabilidad exclusiva del director, aunque a ellos se debe la composición y buena parte de la redacción de muchos de los artículos sin firma. La nómina de colaboradores se completaba con los dibujantes y con los fotógrafos, que son quienes confirieron al número su peculiar y cuidada estética que se llevó hasta el más mínimo detalle, desde la tipografía hasta la elección de los grandes titulares, los títulos y las Ilamadas; toda una mezcolanza heterogénea, pero bastante equilibrada, de vanguardismo y tradición periodística. Encabezaba la lista de ilustradores el veterano Teodoro Delgado Ramos -Doroteo- (Boves, 2014), seguidor a ultranza de la más pura línea heroico-simbolista marcada por Sáenz de Tejada, junto a dos jóvenes diseñadores: Restituto de Castro -Resti-, ilustrador publicitario y cultivador de una abstracción expresionista, como la que propugnaba Saura, y José Ramón Poblador, quien llegaría a labrarse un nombre como escultor de trofeos y de obras conmemorativas, según el estilo naturalista de Venancio Blanco. Aunque no figurase en los títulos de crédito propiamente como dibujante sino como autor, hay que incluir también en este apartado a Máximo -Máximo San Juan Arranz-, de quien se recogen en las páginas 3 y 4 fragmentos de su España para usted (Máximo, 1964: 5, 11, 13,14, $28,34,36,46,48,56,58$ y 59), el folleto por antonomasia de los XXV años de Paz -diez millones de ejemplares-, ilustrado con el inconfundible estilo que aplicaría durante su 
dilatada trayectoria a las viñetas periodísticas que le harían famoso. No aparecen recogidos, sin embargo, los nombres de los fotógrafos; la gran mayoría de este material salió de los fondos documentales del Arriba o de los reportajes publicitarios aportados por las empresas anunciadas; pero hay una señalada excepción, la correspondiente a la portada (Vid. Fig.3), obra del fotógrafo Nicolás Muller, de origen húngaro.

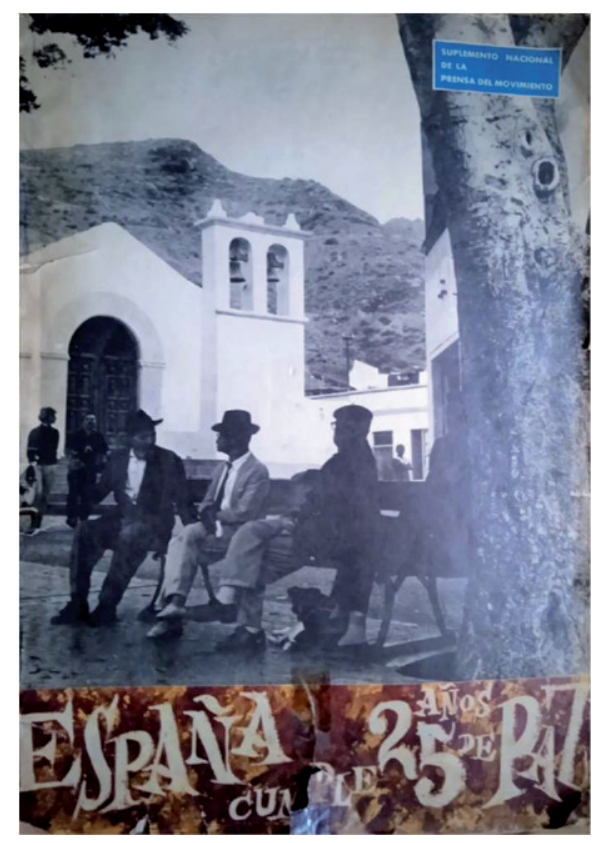

Figura 3. Portada.

Muller, en 1964, se encontraba en pleno éxito profesional gracias al prestigio de su estudio madrileño, a la presencia de su cámara en todos los medios y a la estima que gozaba en los círculos de intelectuales del momento (Girón, 1995: 143-146), que tanto admiraban en él la peculiar visión, entre etnográfica y neorrealista, que ofrecía de España y de sus gentes. Es en esa tendencia donde debe encuadrarse la imagen escogida para la portada; muestra en ella una escena tradicional y bucólica pero con un sorprendente toque de modernidad, pleno de ecos surrealistas: encuadrada por una gran mancha blanca a la izquierda, correspondiente a la iglesia encalada del pueblo tinerfeño de San Andrés y por el trazo vertical oscuro de un tronco de árbol a la derecha, aparecen sentados unos ancianos atemporales y en conversación apacible mientras, en un segundo plano, asisten como espectadores una pareja de jóvenes turistas de aire pop. No encontramos en la instantánea ni una sola referencia a la figura de Franco $^{10}$ o a la victoria en la Guerra, ni tan siquiera a los iconos oficiales de

\footnotetext{
${ }^{10}$ En todo el número sólo hay un retrato oficial de Franco vestido de civil; ocupa la sexta parte de la página 1. Pertenece a la serie de retratos de "aparato", de tres cuartos y postura de perfil, que efectuó el fotógrafo oficial Campúa (Moreno y Demaría, 2013) en 1956. La otra instantánea en que aparece, es de carácter colectivo, también de los años 50 y se le ve junto a Antonio María de Oriol y Urquijo, futuro ministro de Justicia (Vid. Fig.4).
} 
los XXV años, como si, aparentemente, hubiera una clara intención por desligarse tanto del origen fundacional del acontecimiento como de su identificación mimética con el Régimen, propiciando la ilusión de una atmósfera aséptica de mera celebración patriótica y optimista, muy acorde con los tiempos que corrían en todo el Occidente libre. Sin embargo, el contenido de los textos que se encierran entre la portada de Muller y la contraportada, estampada con la publicidad de la Seat, se ajustan mayoritariamente a unos parámetros ideológicos y políticos que poco tienen que ver con las modernas apariencias formales del Suplemento.
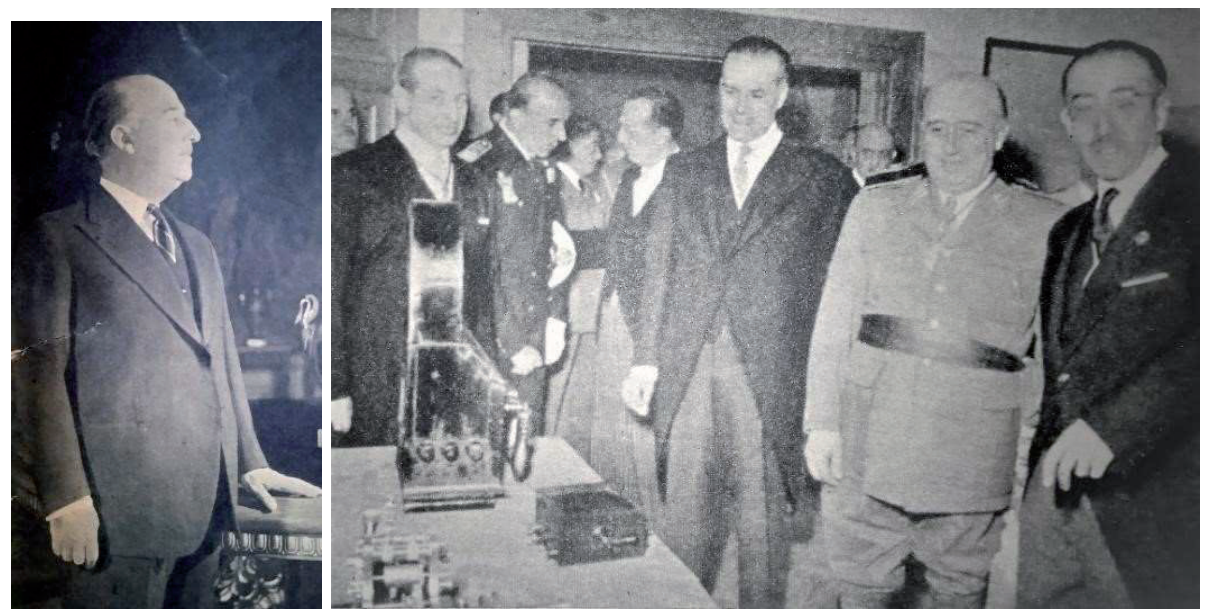

Fig.- 4. Retrato de Franco por Campúa en página 1 (izq.) y segunda fotografía de Franco en el Suplemento junto a Antonio María Oriol de Urquijo, por entonces presidente de la Cruz Roja Española.

A la ausencia de un índice como tal en el número se añade la falta de secciones definidas. Tampoco existe la más mínima ordenación formal. La urgencia por confeccionar el Suplemento a contrarreloj, procurando obedecer las consignas oficiales y conservar las esencias ideológicas del periódico, acabaría contribuyendo a ese aspecto confuso que se vería agravado con la muy diferente respuesta dada por los ministerios ante la petición de material escrito para rellenar tal cantidad de páginas. Este cúmulo de circunstancias terminaría superando a Revilla, como él mismo admite en su artículo "España, de alta": "el espacio y el tiempo son enemigos naturales de todo propósito de esta índole". Aun así, pueden distinguirse en los textos cuatro grandes grupos a tenor de su contenido y procedencia, componiendo un reparto relativamente equilibrado (Vid. Gráfico 2).

El primero de ellos sería el de los escritos doctrinales, que funcionan a modo de unos muy sui generis editoriales; el segundo lo integran los reportajes e informes sobre la situación -o su evolución en el último cuarto de siglo- socioeconómica y cultural de España. En cuanto a los restantes dos apartados son mucho más precisos, menos improvisados y más homogéneos en cuanto a la extensión respectiva o al nivel de calidad periodística. Uno era una encuesta -con dos únicas preguntas- a trece destacadas personalidades del Régimen sobre el 1 de abril de 1939; en cuanto al otro, 
se trataba de una serie compuesta por veinticinco crónicas sobre cada uno de los veinticinco años de Paz.

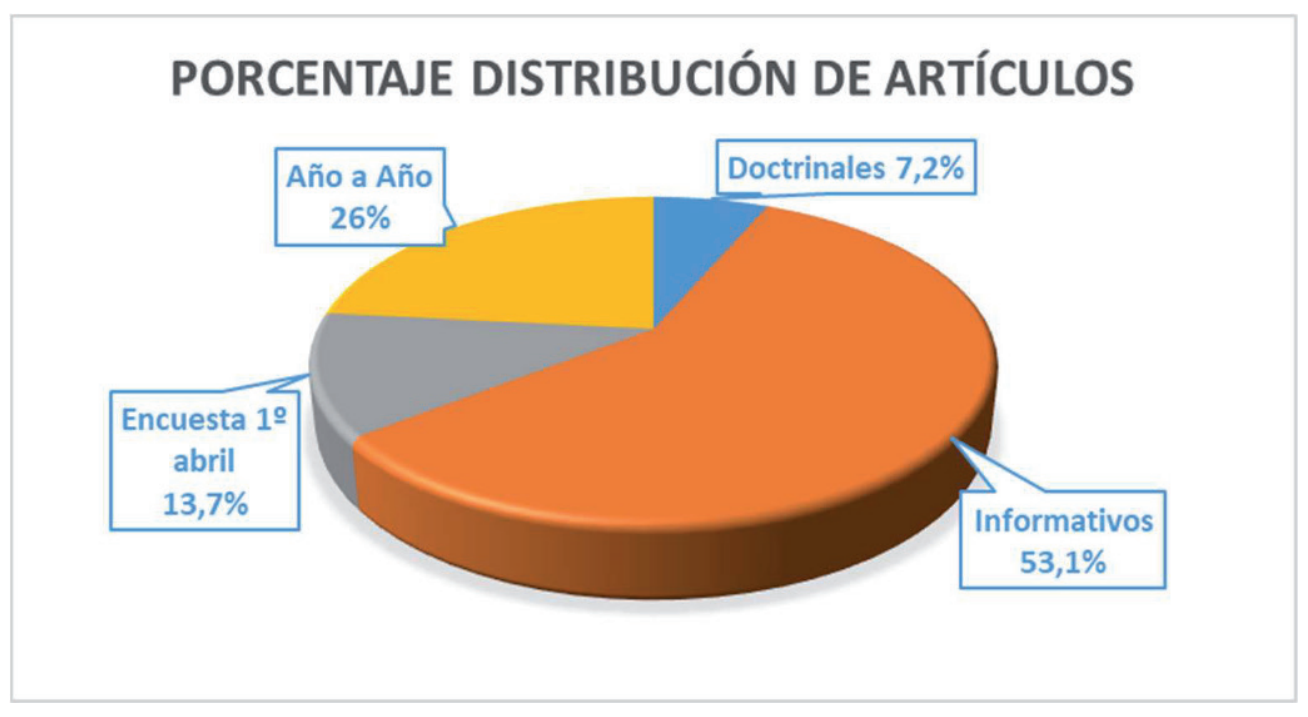

Gráfico 2. Agrupación de artículos del Suplemento Nacional según contenido y forma.

Siete es el número de las colaboraciones que podríamos considerar como una especie de editorial fragmentado. La principal pieza de este bloque corresponde al artículo de José Solís Ruiz, el ministro secretario general del Movimiento y que estaba empeñado entonces en una revitalización de los Sindicatos Verticales (Amaya, 2010: 510); también pretendía dotar al Régimen de una cierta apertura interna para ampliar su base social, idea compartida por su amigo y protegido Manuel Fraga. Solís escribe en la página 1 "Impulso de 25 años", un apasionado discurso con la retórica habitual, con las tradicionales menciones a la Guerra Civil y a sus consecuencias: "Esta España nació de una guerra trágica. En 1939 nuestro país estaba materialmente deshecho", y el recuerdo fervoroso del fundador de la Falange junto con el reconocimiento sin límites a Franco: "Sobre la palabra de José Antonio, la voluntad española se alzó, y, bajo el gesto sereno de Francisco Franco, fuimos capaces de salir de la frontera, de soslayar las dificultades inmensas que la naturaleza y nuestros implacables enemigos tendieron a nuestro paso"; aunque también aprovecha la excusa de la celebración de los XXV Años para presentar las líneas maestras de su proyecto reformista:

En estos años, al tiempo que nuestras instituciones maduraban y se concretaban, adquiriendo firmeza definitiva, el sindicalismo se extendía, física y espiritualmente, por toda la Nación, configurando el sistema nervioso de la justicia social y de la eficacia productiva españolas [...] Somos un país con un pasado hermoso, pero esencialmente somos un país que quiere también tener un hermoso futuro.

La citada colaboración de Revilla, "España, de alta", alcanza un tono más encendido que el de Solís, similar al que se había utilizado hasta entonces en las anteriores 
celebraciones del 18 de julio por parte de los sectores más rabiosamente azules, aquellos que hasta desconfiaban de Solís y de lo que representaba. Llama la atención la imagen de la Guerra como una larga intervención quirúrgica en un organismo enfermo, con resultados diferidos en el tiempo:

Esto, insólito en los anales de la Patria, ha costado lo suyo. Primero, la cruenta y difícilmente olvidable operación bélica. Tres años largos de quirófano, tres años dramáticos y terribles. Después, una convalecencia penosa, amenazada por las convulsiones feroces del exterior, debatiéndose en una alucinante contienda, más las congojas del trauma padecido. Larga convalecencia si se quiere, pero insoslayable, de la que España sale más vinculada a sí misma que nunca. Ahora, de alta.

Revilla finaliza con una loa a la revolución pendiente joseantoniana, una referencia cuidadosamente descartada de todos los discursos de Fraga y su equipo en 1964: "Para evitarlo, cualquier cosa menos creer que con la Paz se gana todo. No. La paz burguesa, sosa, facilona y cómoda es orden hoy y guerra mañana. Nosotros entendemos una Paz despierta, inquieta, recreadora, florecida de enjundias y de vivacidades, con los pelos de la ilusión siempre en punta". En la misma línea guerracivilista y con el recuerdo permanente a los caídos y a los elementos simbólicos fundacionales del falangismo, se insertan los dos textos de Rafael Sánchez Mazas recuperados exprofeso para la ocasión: la "Oración de los caídos" (Burguera, 2012: 519-532), aparecida en 1938, y "El Escorial hoy. Herrera, viviente", que vio la luz en 1939. La justificación que acompaña al último de los títulos, supone toda una declaración de intenciones, sin matices:

Hemos considerado que no podía faltar en este número la colaboración de Rafael Sánchez-Mazas, maestro de prosistas españoles y, probablemente, la mente que mejor interpretó un nuevo concepto de España.

Incorporamos, precisamente, la mejor convocatoria de su voz lírica y profunda a una visión arquitectónica de la Patria, encarnada ayer, hoy y mañana en ese pasmo glorioso que es El Escorial, al que la España que ha ido forjándose en estos veinticinco años ha dedicado sus mayores cuidados, atenciones y ternuras, como el símbolo que es de la España eterna.

Este recurso a la poesía falangista más reconocible -y más combativa- prosigue con la inclusión de otro conocido poema bélico, "Alférez Provisional", escrito por Foxá en memoria de su primo Pío García-Escudero y que llegó a convertirse en una especie de himno oficioso para los oficiales provisionales del bando nacional. Se cierra este apartado lírico tan grato al falangismo más purista (Vivó, 2017) con una página entera, obra de Federico Muelas y Pérez de Santa Coloma11 (Muela, 2010) titulada “Pequeña

\footnotetext{
${ }^{11}$ Muelas seguía siendo, a pesar de su activismo, un poeta muy minoritario que no vio publicado un libro completo hasta 1959. Su inclusión, junto a figuras de la talla de Foxá o de Sánchez Mazas se explica por
} 
Elegía" e integrada por tres poemas con ciertos ecos a lo Paul Claudel- "Mi llamada a los muertos", "Soneto", "Tierra de cimientos"-.

El contraste de toda esta carga retórica, ideologizada hasta el extremo, frente a la prosa ligera y humorística que caracterizaba la contribución de Máximo, resulta chocante. Pero no hay porqué pensar que su inclusión se debiera a una imposición por parte del Ministerio de Información y Turismo. Desde 1962, Máximo venía colaborando en publicaciones del Movimiento como Juventud y en el mismo Arriba, especialmente en el suplemento cultural, además de sus otras incursiones en el diseño editorial y en diversas revistas de humor que le llevarían a integrarse, finalmente, en la plantilla del diario Pueblo en octubre de 1964 (Conde, 2014: 15-29). Aun así, la participación del escritor-dibujante suponía la nota más discordante del Suplemento Nacional y eso que la parte que se reprodujo de su folleto era totalmente inocua ${ }^{12}$ instrucciones de viaje, información sobre los toros, la Guardia Civil y la paella, el carácter español- tal y como reconoce la forzada entradilla que lo acompaña: "Muy seleccionados y prietos, por imperativos de espacio, ofrecemos unos dibujos comentados del genial Máximo, recogidos en una publicación sensacional del Ministerio de Información y Turismo. Si bien van dedicados especialmente a los turistas, sirvan también a los españoles, permanentes turistas de nuestra propia Patria".

Los artículos informativos ocupan más de la mitad del Suplemento. Como cabría suponer, a pesar del intento de algunos por aparentar una cierta imagen de ecuanimidad y de eficiencia estadística acorde con los aires tecnocráticos a la moda, todos resultan transidos de triunfalismo y de carácter propagandístico, si bien no siempre en las mismas dosis. Son cincuenta y una las piezas que componen este apartado, cuya pretensión era ofrecer al lector una síntesis del proceso de transformación vivido en España desde la posguerra hasta entonces, dando el protagonismo prioritario a la actuación gubernamental y el secundario -o complementario, más bien-, a la sociedad civil. Este apartado se dejará en manos de los distintos ministerios y de las empresas anunciadoras, limitándose el equipo de redacción a una mera labor de recogida y presentación, sin aportación investigadora alguna. Apenas se hizo uso de las informaciones que sobre este asunto había encargado el Ministerio de Fraga a través de múltiples colecciones documentales, como las editadas por el INE, por "Publicaciones Españolas" o por el "Servicio Informativo Español"; datos que, sin embargo, fueron la base informativa de la

la participación que tenía en Arriba y, probablemente, por su relación personal con Revilla y con el propio Fraga, que le incluyó en su equipo ministerial como asesor cultural.

${ }^{12}$ Algunos párrafos del folleto provocaron ciertas suspicacias, especialmente los dedicados a la Guerra Civil: "Todavía recuerda el mundo aquella guerra de tres años a la que la Iglesia católica dio el nombre de Cruzada. No diremos que en ella todos los buenos estaban de una parte y todos los malos de otra, entre otras cosas porque la bondad y la maldad siempre andan mezcladas" (Máximo, 1964: 54). 
faraónica Exposición Conmemorativa alojada bajo la vanguardista cúpula de Emilio Pérez Piñero (Pérez Belda y Pérez Almagro, 2016: 146-155) y montada en la lonja del Ministerio de Fomento. Ni siquiera se recurrió a los aludidos folletos de España para Usted y las colecciones de carteles, plagados todos de datos estadísticos.

La dejación y la indisimulada falta de entusiasmo, tendrían como consecuencia un resultado final muy por debajo de las pretensiones iniciales, puesto que el panorama que se ofrecía al lector del Suplemento se limitaba a muy pocos aspectos de la realidad socioeconómica española $y$, además, presentados de forma totalmente descompensada y fragmentaria respecto al verdadero peso específico de cada uno de estos sectores. A la ausencia absoluta de datos sociológicos elementales sobre referentes tan básicos como la demografía, la sanidad o la enseñanza, se une la ausencia casi total de las contribuciones informativas de los Ministerios considerados como "mayores" -Asuntos Exteriores, Hacienda, Justicia, Educación y Comercio-; un vacío que afectará también a otros Ministerios "menores" -Vivienda e incluso Ejército, Marina y Aire- (Vid. Gráfico 3).

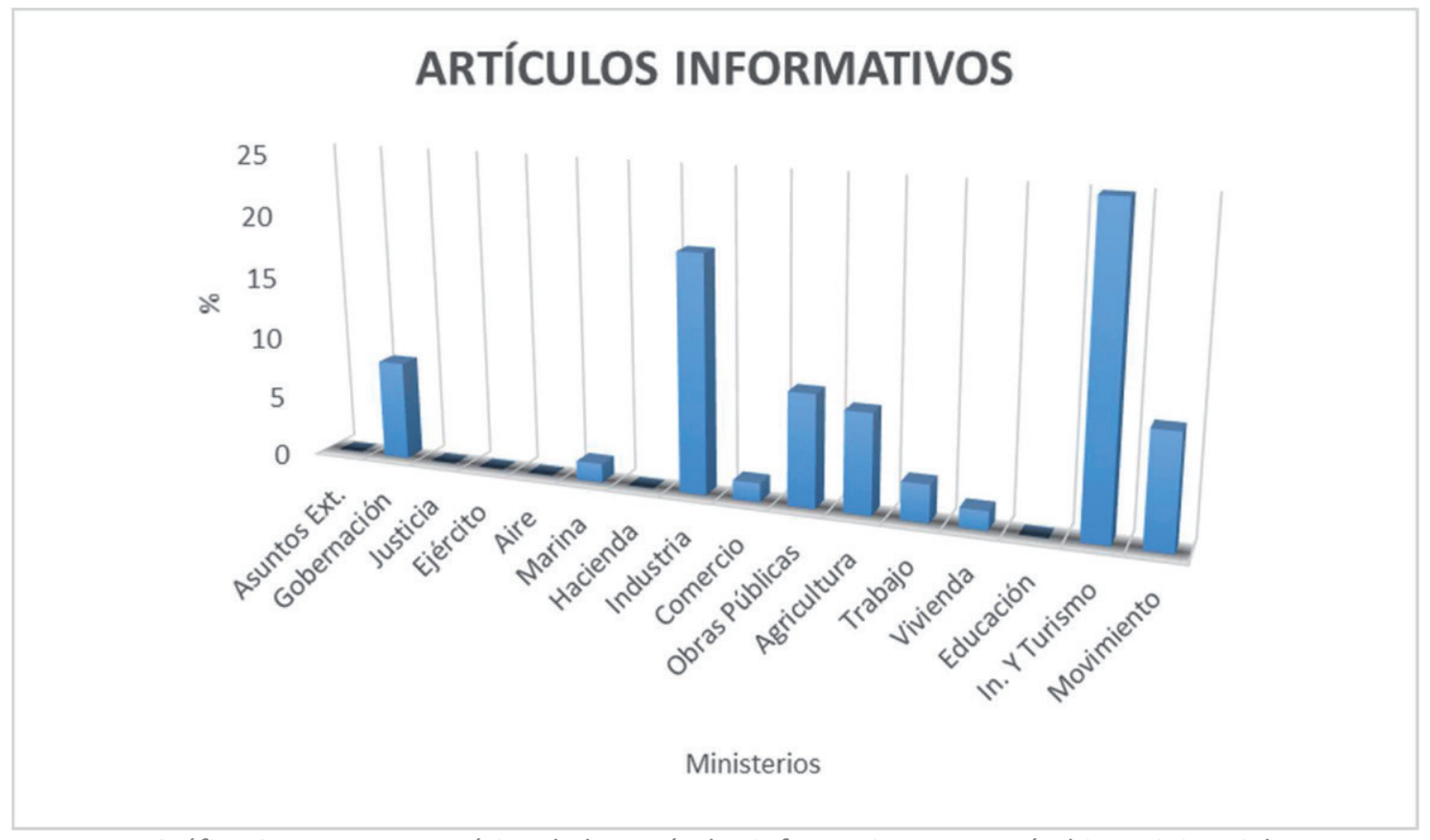

Gráfico 3.- Reparto temático de los artículos informativos por su ámbito ministerial.

Surge la duda de si la culpa de tales ausencias se debe, sobre todo, al desinterés por parte de determinadas autoridades ministeriales en colaborar con el Arriba o a una intención, más o menos consciente, del coordinador del número por devaluar a aquellos sectores del franquismo con los que el Arriba no comulgaba. El mayor número corresponde, como es obvio, al Ministerio de Información y Turismo; al fin y al cabo, actuaba como el motor dominante del evento, a pesar de las constantes menciones al carácter interministerial del mismo. Sin embargo, no figuró en sus páginas la firma de Fraga; de hecho, sólo tres ministros, además de Solís, obligado por la naturaleza de su cargo de secretario general del Movimiento, cedieron sus firmas para prestigiar un 
tanto esta sección; dos resultaban del total agrado de la línea defendida por el periódico, ambos militares: Camilo Alonso Vega -Gobernación- y Jorge Vigón -Obras Públicas-; el tercero no lo era tanto, al tratarse de uno de los que estaban más cercanos por entonces a Carrero, el también militar almirante Pedro Nieto Antúnez Marina- a quien se incluyó para que estuviera representado, al menos, uno de los tres ministerios militares. El artículo de Nieto -"España se mira en el mar. Balance de una política naval"-, destaca entre los demás por su tono realista, casi crítico: "En los veinticinco años de paz el deseo que caracteriza a nuestra política naval ha tendido a la supervivencia [...]. Esto, que dicho así pudiera parecer mezquina empresa, representa empero un redondo triunfo [...]; del entendimiento con los Estados Unidos brota nueva savia para vigorizar la política naval española". En cuanto a los demás ministros, optaron mayoritariamente por delegar esta tarea en sus cuadros técnicos ministeriales (Vid. Gráficos 4 y 5).

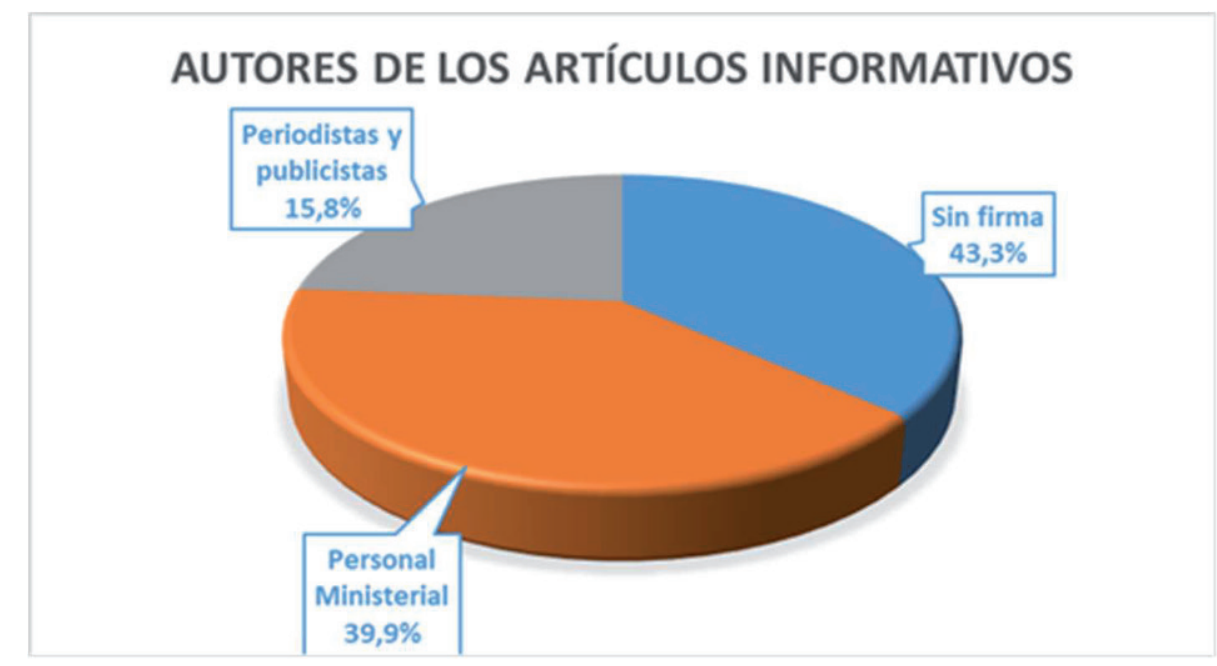

Gráfico 4.- Distribución porcentual según la autoría de los artículos informativos.

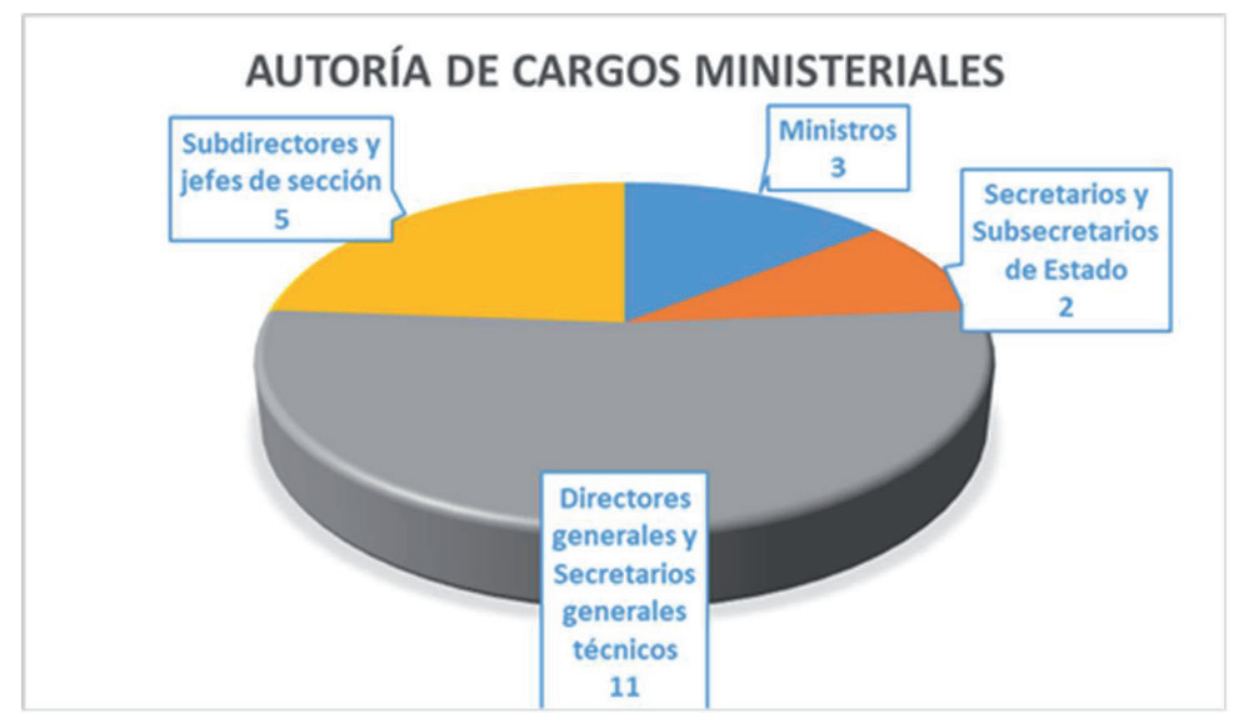

Gráfico 5. Distribución específica según categoría de los autores con puestos ministeriales en la sección de artículos informativos. 
Resulta evidente que existía un sordo rechazo hacia los titulares que presidían aquellos ministerios ausentes -o apenas representados por un artículo de compromiso- en el Suplemento. Castiella -Exteriores- se consideraba, a los ojos del falangismo ortodoxo, una especie de traidor que apostató de sus ideales imperialistas de los años 40, defendiendo una postura abierta a los pactos con los Estados Unidos y a la descolonización; de Antonio Iturmendi -Justicia-, les separaba su condición de tradicionalista monárquico a ultranza; peor aún eran las relaciones con Mariano Navarro Rubio (Hacienda) y con Alberto Ullastres Calvo (Comercio), por su adscripción de tecnócratas creadores del demonizado Plan de Estabilización y miembros del Opus Dei; a José María Martínez y Sánchez-Arjona (Vivienda), no le perdonaban el haber sustituido rápidamente a uno de sus iconos, el dimitido Arrese en 1960 (Candela, 2017: 281-292); este carácter de intruso se extendía también al general Camilo Menéndez Tolosa (Ejército), quien al suceder a Pablo Martín Alonso en febrero de 1964, se había saltado el escalafón por encima de Rafael García-Valiño, militar muy del agrado del falangismo ortodoxo y entonces caído en desgracia; en cuanto a Manuel Lora Tamayo, arrastraba el sambenito de ser un contemporizador frente a los conflictos universitarios.

Ahora bien, ¿cómo explicar, siguiendo esta pauta de las posibles antipatías o simpatías que provocaban los ministros, que la segunda cartera ministerial con mayor número de aportaciones fuera precisamente la de Industria? El ocupante de la misma era Gregorio López-Bravo, que completaba la odiada triada tecnocrática, con los agravantes de su condición de supernumerario del Opus Dei y protegido especial de Carrero. Lo cierto es que resultaba imposible dejar a un lado el proceso acelerado de industrialización para hacer evidentes el progreso y la modernización asociados al sistema. El asumir lo de "la décima potencia industrial del mundo" (Banco Mundial, 1962 y Fuentes Quintana, 1963), obligaba a hacer una loa que comprendiese por igual al INI y a las empresas privadas, a los grandes avances técnicos o energéticos y a las bondades sociales de las factorías modelo, reduciendo a la mínima expresión el enfrentamiento que se daba entre unos arrolladores planteamientos liberales y los autárquicos, ya en franca retirada (Beltrán, 1994). Éste es el sentido que imprime José María Fontana Tarrats -falangista catalán, fundador del influyente semanario Destino y secretario por entonces de la Cámara de Comercio de Madrid y del Tribunal de Defensa de la Competencia-, a su artículo "La industrialización, objetivo logrado"13, donde afirma que "la industria es nuestra auténtica liberación y la posibilidad única de redención nacional. Ella permitirá y forzará la posible racionalización de la agropecuaria. Ella nos dará el bienestar que nuestra Etnia exige y la Gea nos niega".

El otro indicador de progreso que se exhibe es la puesta en marcha de la Seguridad Social, un proyecto que asumieron como triunfo propio los sindicatos verticales,

\footnotetext{
${ }^{13}$ Resumen de su libro La lucha por la industrialización de España, Madrid, Ateneo, 1953.
} 
reducto de las esencias falangistas en el Estado. El artículo de Rafael Cabello de Alba, director general de Previsión -“Una victoria de la Paz: la Seguridad Social”- ocupa hasta tres páginas enteras y contiene algunos de los textos más combativos, ideológicamente hablando14: "Todos los planes de la Seguridad Social, conteniendo las más progresivas reformas, han nacido en estos últimos años de los efectos económicos y sociales de las grandes guerras [...]. La guerra civil hizo ver la necesidad de potenciar los beneficios de la Previsión o Seguridad Sociales".

Como contrapeso a la actividades industriales y turísticas y a la extensión de la Seguridad Social que configuraban el santo y seña de los nuevos tiempos, la agricultura aparece sobredimensionada, a pesar de que todavía concentraba al $36 \%$ de la población activa, a la mitad de las exportaciones y suponía el $16 \%$ del Producto Interior Bruto (Abad, García y Muñoz, 1994: 73). De entre todas las comunicaciones sobre el sector agropecuario, sobresale la de Tomás Allende y García-Baxter, futuro ministro de Agricultura y por entonces presidente de la Cámara Nacional de Labradores y Ganaderos, porque en su artículo -“Agricultura y Desarrollo"-, expone la situación real de atraso que sufría el campo español y la necesidad de industrialización y capitalización del mismo, alineándose con las propuestas desarrollistas del grupo de López Rodó: "Nos enfrentamos con el problema de cuáles deben ser las acciones públicas y privadas para romper este círculo vicioso".

Capítulo aparte merecen las dos únicas colaboraciones culturales - "El espíritu y la cultura en 25 años paz" y "25 años de poesía española. Breve selección antológica"correspondientes a Dámaso Santos Gutiérrez -premio nacional de poesía José Antonio, 1968-, el agudo crítico literario de Pueblo -llegaría a ser director de su suplemento cultural- y colaborador en Arriba y Estafeta Literaria bajo el seudónimo de César Villamañán. Ambas intervenciones, además de ser en sí unas rigurosas síntesis concebidas con sólidos criterios académicos, conforman un muestrario de la visión cultural falangista más ortodoxa, la que se entendía como una provocación permanente -aunque bastante consentida- hacia los sectores conservadores y católicos del franquismo. Esta auténtica pose se exhibía a modo de banderín identitario para marcar una zona propia y exclusiva, definida por la independencia artística y personal, aunque buena parte de sus seguidores se debatiera, contradictoriamente, entre la fidelidad o la ruptura con el sistema al que se acogían bajo el amparo protector y siempre cómplice del Movimiento. En los dos escritos de Santos aparecen todas y cada una de las consabidas interpretaciones falangistas sobre la literatura española que iba desde fines del XIX hasta 1964 (Mainer, 1971: 60-64, Díaz y Uribe, 2005). En primer lugar, la consideración de la poesía como el género literario por excelencia, siguiendo así las preferencias personales de José Antonio (García de Tuñón, 2003); también, la

\footnotetext{
${ }^{14}$ Algo que sorprende en quien más adelante sería un defensor temprano de la apertura política -1971-, enfrentado a los sectores más inmovilistas del Régimen (Rodríguez Jiménez, 1994: 151).
} 
admiración por las tres grandes generaciones literarias anteriores a los años 30, con especial consideración, por encima de la discrepancia política, hacia Antonio Machado, Juan Ramón, Miguel Hernández, Rafael Alberti y Lorca; igualmente, el reconocimiento como asumidos precedentes intelectuales de los autores regeneracionistas $y$, sobre todo, de Ortega y de sus discípulos -Marías- y de Eugenio D’Ors; muy importante es la reivindicación de la labor cultural y propagandística llevada a cabo durante la Guerra y en los primeros años de la Posguerra que él presenta de esta manera:

Las memorables horas burgalesas [...] una veintena de nombres españoles nacionalmente conocidos han salido de aquel grupo: los poetas Ridruejo, Rosales y Vivanco; los dibujantes y pintores Cabanas, Escassi, Pruna y Caballero; el novelista y dramaturgo Torrente Ballester [...] el novelista Agustí; los profesores Tovar, Salas, yo mismo [...] Foxá [...] Luis Escobar, uno de los arcades de nuestro teatro, y luego el malogrado Aladrén, y Pedro Salvador, y Juan Ramón Masoliver, y Carlos Alonso del Real.

y que luego continúa durante los años 50 y 60, apuntándose como propias buena parte de la promoción cultural y de la actividad editora de esas dos décadas -Ínsula, Índice...-. Hay presente también un asumido orgullo por la nómina de literatos salidos -y entrados- de sus filas, desde los tiempos heroicos de la fundación del Partido hasta el momento presente que se cierra con los nombres de dos jóvenes promesas: Gloria Fuertes y Manuel Alcántara. Es evidente el deseo por mostrar la cercanía y la contribución a las vanguardias de cada momento, sin prejuicios de ningún tipo hacia sus autores más señeros -Cela, Laforet, Sánchez Ferlosio, Aldecoa, Buero, Alfonso Sastre, Hierro, Celaya, Blas de Otero, Claudio Rodríguez, Valente, Goytisolo, Gil de Biedma...-; por último, señala la intención de acercarse a los escritores del exilio, denominados eufemísticamente como "escritores españoles emigrados" -Sender, Max Aub, León Felipe, Guillén, Cernuda...- para lograr un reencuentro cultural que facilitase la reconciliación histórica en un futuro.

La tercera de las secciones, la de la encuesta sobre el día de la Victoria -"1. ¿Dónde y cómo vio el 1 de abril de 1939? 2. ¿Qué significación le dio a esa fecha?"-, basa su interés más en el perfil de los entrevistados que en las respuestas propiamente dichas, todas bastante previsibles. El que la fecha elegida fuera el final de la Guerra en vez del 18 de julio no supondría atenuación alguna en la interpretación tradicional del acontecimiento, ni un giro significativo hacia las posturas favorecedoras del olvido histórico o de cualquier otro mínimo gesto pacifista. No hay más que mirar la lista de los trece encuestados (Vid. Tabla 1).

\section{NOMBRE PRESENTACIÓN}

1.Emilio Romero "Novelista, autor teatral y periodista del más alto prestigio.

Gómez Consejero Nacional. Vieja Guardia. Director del diario Pueblo". 
2.Raimundo

Fernández

Cuesta

3.Carlos Asensio

Cabanillas

4.Ángel González

de Mendoza y

Dorvier

5.José María

Pemán y Pemartín

6.Carlos Martínez de Campos y

Serrano

7.Rafael GarcíaValiño y Marcén

8.Eduardo

Ezquer

Gabaldón

9.Eduardo
"Notario. Exministro de Agricultura, Justicia y Secretario General del Movimiento. Embajador de España en el Brasil e Italia. Consejero Nacional del Movimiento".

"Ilustre soldado de las campañas de África y de la Cruzada. Jefe de la Casa Militar. Ex Ministro del Ejército"

"Ilustre militar acreditado en las campañas de África y de la Cruzada. Ex Capitán General de Región militar, con gran prestigio como hombre de Estado Mayor. Actualmente director de la Escuela Superior del Ejército".

"Poeta y escritor. Luchador infatigable de la causa nacional como diputado tradicionalista durante la República; como anteriormente colaborador del Gobierno del General Primo de Rivera. Ex presidente del Instituto de España, de la Real Academia Española, presidente del Consejo privado del conde de Barcelona, destacadísimo por sus artículos periodísticos en los que ha alcanzado un nombre de primerísima actualidad".

"Duque de la Torre, insigne militar perteneciente al Cuerpo de Artillería. Escritor ilustre, académico, historiador".

"Una de las más gloriosas figuras del generalato español. Brillantísimo jefe de la Cruzada. Ex Alto Comisario de España en Marruecos, director de la Escuela Superior del Ejército, jefe del Estado Mayor Central, Capitán General de la primera región militar. Consejero Nacional del Movimiento".

"Falangista rebelde, consejero del primer y segundo consejo nacional de José Antonio, primer Jefe Provincial de Badajoz hasta finales de 1935 y fundador nacional de la Falange Española. Ezquer tan reiteradamente citado en la Historia de la Cruzada Española, en Biografía apasionada de José Antonio, de Ximénez de Sandoval; Madrid de corte a checa, del conde de Foxá; Vieja Guardia de Montes Agudo; Falange: a History of Spanish Fascism de Stanley G. Payne, y numerosos libros más, además de docenas de periódicos y revistas nacionales y extranjeras, mereció de la clara pluma de Víctor de la Serna, el calificativo de 'puro como el aliento de los ángeles', cuando hablaba de las escuadras extremeñas y de su Centurión-jefe.

Ezquer, citado por José Antonio como Jefe de Escuadras ejemplares en Barcelona, Villagarcía de Arosa y otros puntos de su peregrinación, cuenta con el mayor número de citas dispensadas en los periódicos de combate de Falange, $F E$ y Arriba, y hasta con la excepción de un artículo, 'Ezquer y su gente' en el número 5 de este periódico últimamente citado".

“Heroico aviador. Ex Ministro del Aire. Teniente General jefe 


\begin{tabular}{|c|c|}
\hline $\begin{array}{l}\text { 10.Eduardo Aunós } \\
\text { Pérez }\end{array}$ & $\begin{array}{l}\text { "Sociólogo eminente. Ex ministro del Gobierno del General } \\
\text { Primo de Rivera y del Estado Nacional. Presidente del Tribunal } \\
\text { de Cuentas del Reino". }\end{array}$ \\
\hline $\begin{array}{l}\text { 11.Pedro González- } \\
\text { Bueno y Bocos }\end{array}$ & $\begin{array}{l}\text { "Ilustre director de Empresas. Ex ministro del Estado Nacional. } \\
\text { Consejero Nacional del Movimiento". }\end{array}$ \\
\hline $\begin{array}{l}\text { 12.Enrique García- } \\
\text { Ramal Cellalbo }\end{array}$ & $\begin{array}{l}\text { "Ingeniero industrial, director gerente de Altos Hornos de } \\
\text { Vizcaya S.A., consejero del Consejo de Economía Nacional, } \\
\text { Procurador en Cortes. El Movimiento le sorprende en } \\
\text { Barcelona, donde interviene activamente en el Alzamiento, } \\
\text { tomando parte en él y resultando herido grave en la } \\
\text { madrugada del } 19 \text { de julio. Es hecho prisionero y cuando logra } \\
\text { fugarse a la España Nacional se incorpora al frente y ve el final } \\
\text { de la guerra como teniente provisional de Artillería". }\end{array}$ \\
\hline $\begin{array}{l}\text { 13.Felipe Bertrán } \\
\text { Güell }\end{array}$ & $\begin{array}{l}\text { "Destacadísima personalidad barcelonesa. Patriota } \\
\text { extraordinario. Director del Instituto de Cultura Hispánica en } \\
\text { Barcelona". }\end{array}$ \\
\hline
\end{tabular}

Tabla 1. Cuadro-resumen de los entrevistados.

Esto no quiere decir que fuera una muestra totalmente monocolor y homogénea (Vid. Gráfico 6). Había personalidades entrevistadas que ya no ocupaban altos cargos y también los había caídos en desgracia dentro de los círculos de poder -FernándezCuesta, García-Valiño-; otros permanecían en el mayor olvido -Aunós, González-Bueno, Bertrán Güell-. Junto a los tenientes y capitanes generales, los civiles representaban un abanico más amplio, en edad, procedencia política y profesional, hasta el punto de incluir a un pintoresco disidente hedillista, Ezquer Gabaldón (Payne, 1985: 177) glorificado con la presentación más extensa de todas. Sobresalen, por notoriedad y popularidad, dos nombres, los de Emilio Romero y José María Pemán quienes ofrecieron las respuestas más chocantes y originales. Romero, con su mordacidad habitual (Amilibia, 2005), sostiene que "Yo era entonces un inocente idealista; después de veinticinco años mantengo el idealismo hacia cosas menos fantásticas y ya no soy inocente"; Pemán, más irónico, compara al 1 de abril con "la revolución francesa, la Guerra de Secesión americana o el Pacto inglés de la Corona y el pueblo después de Cromwell", toda una boutade. 


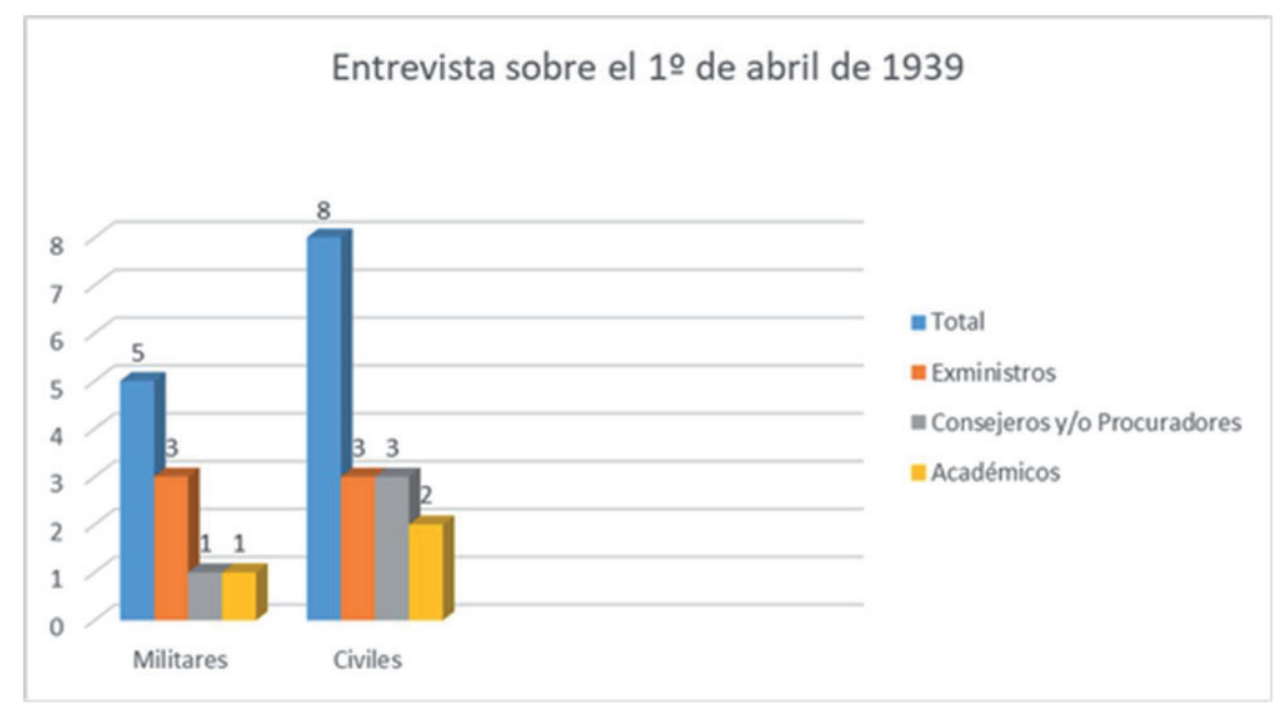

Gráfico 6. Ámbito y cargos de los entrevistados.

La sección sobre la crónica desde 1939 a 1963 constituye la parte más cuidada del Suplemento y conforma una línea narrativa común (Giménez, 2015: 11-45), a pesar de que cada uno de los veinticinco autores dispusiera de una cierta libertad temática y de extensión. Prácticamente, todos ellos eran firmas populares y reconocidas profesionalmente (Vid. Gráfico 7).

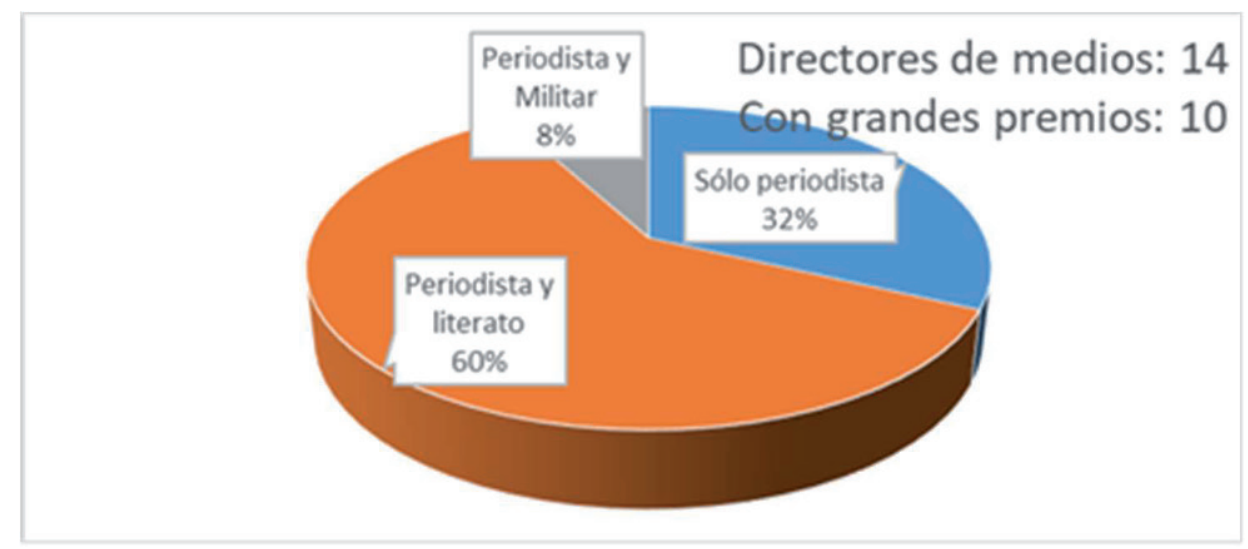

Gráfico 7. Perfil y categoría profesional de los autores de las crónicas de los 25 años de paz.

Excepto en dos de los casos -Ariel y de Aguirre-, cada escrito iba acompañado del retrato del periodista.

\begin{tabular}{|c|c|}
\hline TÍTULO & AUTOR \\
\hline $\begin{array}{l}1939 \text { "Señores: vamos a hacer } \\
\text { España" }\end{array}$ & Tomás Borrás Bermejo \\
\hline 1940 “La neutralidad" & Felipe Ximénez de Sandoval y Tapia \\
\hline 1941 "Un año decisivo" & Jesús Vasallo Ramos \\
\hline
\end{tabular}




\begin{tabular}{|c|c|}
\hline 1942 “Paz en la vorágine” & Antonio de Obregón Chorot \\
\hline 1943 "Italia fuera de combate" & Luis Ponce de León Ronquillo \\
\hline $\begin{array}{l}1944 \text { "Una salud a prueba de } \\
\text { complot" }\end{array}$ & Juan Aparicio López \\
\hline 1945 "Los orígenes del cerco" & Luis (Martínez) de Galinsoga y de la Serna \\
\hline $\begin{array}{l}1946 \text { “El año de la producción } \\
\text { artística” }\end{array}$ & Ignacio Agustí Peypoch \\
\hline $\begin{array}{l}1947 \text { "Signos de un año } \\
\text { nacional: unidad y firmeza" }\end{array}$ & Francisco Casares Sánchez \\
\hline $\begin{array}{l}1948 \text { "E de Esperanza Europea, A } \\
\text { de amor americano" }\end{array}$ & Salvador Jiménez López \\
\hline "Desde la nada" & José Ramón Alonso Rodríguez-Nadales \\
\hline $\begin{array}{l}1950 \text { "Se hace justicia a las } \\
\text { razones de España" }\end{array}$ & Juan Carlos Villacorta Luis \\
\hline $\begin{array}{l}1951 \text { "Entre la España } \\
\text { recuperada y el comienzo de su } \\
\text { expansión" }\end{array}$ & Julio de Urrutia Echániz \\
\hline "Sin ceder un palmo" & Domingo Manfredi Cano \\
\hline $\begin{array}{l}1953 \text { "Los pactos con } \\
\text { Norteamérica" }\end{array}$ & Ángel Ruiz Ayúcar \\
\hline $\begin{array}{l}1954 \text { "El año de la llegada del } \\
\text { 'Semiramis'" }\end{array}$ & Rafael Manzano Monís \\
\hline $\begin{array}{l}1955 \text { "El año de la entrada de } \\
\text { España en la ONU" }\end{array}$ & Pablo Martínez Palomero \\
\hline $\begin{array}{l}1956 \text { “Vuelve España, por Dios, a } \\
\text { donde fuiste..." }\end{array}$ & Lucio del Álamo Urrutia \\
\hline 1957 “Protagonista, el pueblo" & Carlos Ribero ${ }^{15}$ \\
\hline $\begin{array}{l}1958 \text { “Hay que apretarse el } \\
\text { cinturón” }\end{array}$ & Javier de Aguirre \\
\hline $\begin{array}{l}1959 \text { "El año } 1959 \text { tiene un } \\
\text { título: } 30 \text { de marzo" }\end{array}$ & Fernando Cañellas Rodríguez \\
\hline 1960 “La búsqueda de la & Francisco Sanz Cagigas \\
\hline
\end{tabular}

\footnotetext{
${ }^{15}$ Seudónimo de Carlos Rivero Troncoso.
} 


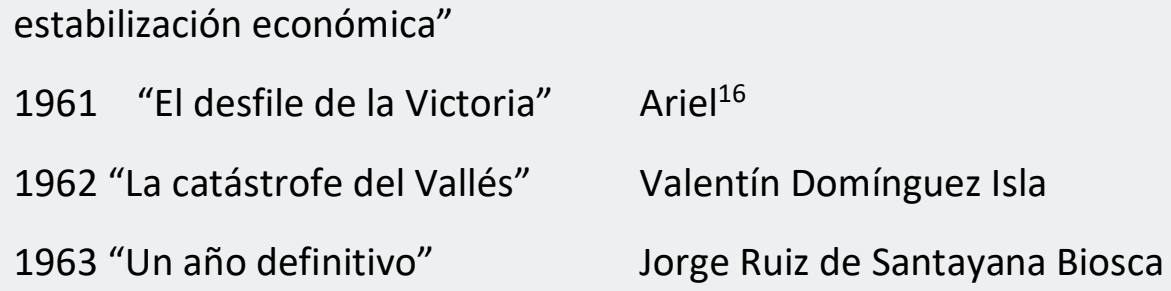

Tabla 2. Cuadro-resumen de las crónicas de los 25 años de paz.

Este grupo de firmas (Vid. Tabla 2), da una idea bastante aproximada del tipo de periodismo -y de periodistas- que integraban la Prensa del Movimiento en particular; si bien, el Suplemento admitió a algunos nombres ajenos entonces al grupo editorial del Estado, como fueron Ignacio Agustí -que dejó Destino por la dirección de Tele-Exprés y la participación en el renovado semanario Triunfo-, Galinsoga -cesado escandalosamente de la dirección de La Vanguardia y ajeno al periodismo desde 1960, o Aguirre -El Pensamiento Navarro-; de todas formas, en aquellos años no existía la exclusividad dominante actual y era muy frecuente la presencia simultánea en distintos medios a la vez. Sorprende la ausencia de periodistas jóvenes (Vid. Gráfico 8); un grupo de edad muy presente, sin embargo, en la redacción de Pueblo, por poner un ejemplo significativo. El firmante con menos años -Salvador Jiménez- tenía 42, mientras los dos decanos -Borrás y Galinsoga-, pasaban de los 73, estando la media en torno a los 54 años. Este condicionante generacional, lleva aparejada la implicación directa de todos ellos en la Guerra Civil, con una militancia política, altamente comprometida en términos generales y ejercida justo antes o durante la propia contienda.

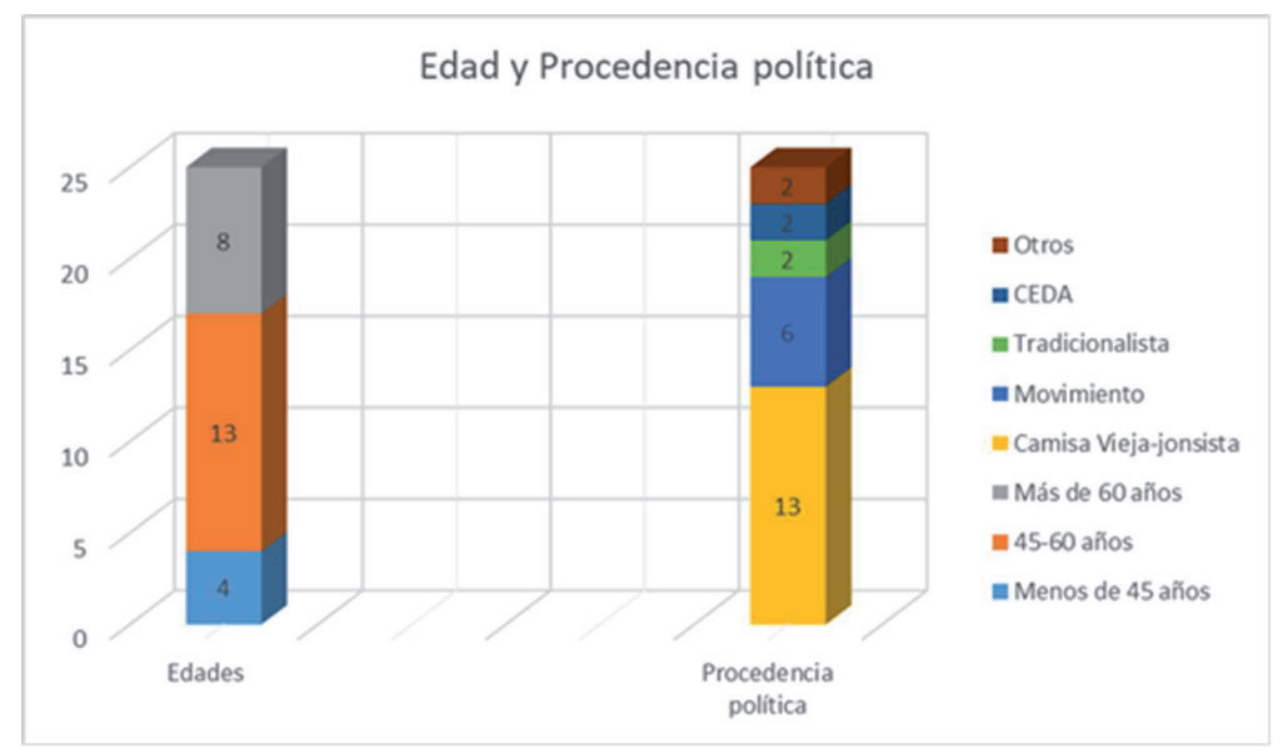

Gráfico 8. Edad y procedencia política original de los autores de las crónicas de los 25 años de paz.

\footnotetext{
${ }^{16}$ Seudónimo de Román Escohotado Jiménez, padre del filósofo Antonio Escohotado Espinosa.
} 
Dicho criterio generacional refuerza el carisma intrínseco al Arriba y explica, a su vez, que la mayoría de los redactores perteneciera a la "familia azul", con un predominio abrumador de los denominados "Camisas Viejas", muy por encima de su presencia real, incluso en los momentos en que este grupo disfrutó de un mayor peso en los distintos gobiernos de Franco y en sus diversas esferas de poder (Ellwood, S.M., 2001: 145 y ss.). En cambio, los periodistas procedentes de las otras familias políticas previas al decreto de unificación de 1937, quedaron reducidos a mínimos testimoniales. Por otra parte, la Escuela Oficial de Periodismo, desde su fundación estuvo bajo el control de la Falange, en la persona de Juan Aparicio López, quien ejercería largamente su dirección -de 1941 a 1945 y de 1951 a 1957- (Tapia, 2001: 232-235), siendo el maestro por antonomasia -y el promotor- de muchos de ellos. El estilo de la escuela resulta bastante fácil de rastrear en el lenguaje y en la sintaxis usados por buena parte de los que pasaron por ella (Rebollo, 1978: 176), sobre todo entre los que no ejercieron otras fórmulas de escritura fuera de la periodística.

En este apartado de las crónicas, no resultó necesario ningún plan previo minucioso, ni tampoco hubo que repartir consignas, puesto que las líneas generales formaban parte del inventario ideológico de los elegidos. La matriz del relato descansa en la identificación incuestionable de la nación con Franco y con su actuación providencial desde el marasmo de partida de 1939, donde todo estaba aún por hacer, hasta la situación ventajosa de 1964 . Sobre esta matriz se asienta la urdimbre explicativa que da cuerpo a los años.

Uno de sus principios confiere a la Guerra Civil la categoría de hecho fundacional e indispensable para construir el porvenir $y$ al que se debe un permanente reconocimiento en la figura de los caídos, siendo José Antonio el primero. Otro, corresponde al protagonismo ejercido por el ideario falangista durante este tiempo y su vigencia atemporal que, supuestamente, cuenta con un poderoso arraigo entre el común de la población por las reivindicaciones de corte social defendidas por la Falange, y por su actuación cultural; esto conllevará, entre otras cosas, la justificación a ultranza de la Autarquía y el encubrimiento sistemático de todo lo relacionado con las pasadas simpatías y afinidades con el Eje durante la IIa Guerra Mundial.

El tercer hilo argumental se identifica con la denuncia de los causantes de los males patrios, especialmente de los sufridos durante la larga posguerra, la etapa mítica considerada como el crisol y el banco de pruebas más decisivo. Establecida la distinción entre los culpables de fuera -la Unión Soviética y el comunismo, Roosevelt, Truman y buena parte de las democracias occidentales, la ONU y los demás organismos internacionales...- y los culpables de dentro -el partidismo liberal, los separatismos, la izquierda, el sindicalismo...-, hay una intención por no demonizar en exceso a los perdedores anónimos de la Guerra, mientras se ataca veladamente a 
aquellos sectores pancistas y sin ideales que se sumaron interesadamente al carro de la Victoria, mostrándose tibios y reticentes a lo que representaba la Falange.

El cuarto hilo director viene definido por la imagen de un Régimen capaz de triunfar frente a todos los obstáculos, que logró permanecer ajeno a los males físicos y morales que asolaban al mundo actual, creando un peculiar sistema autóctono -envidiado en el extranjero- con el que se daba solución a los conflictos sociales y económicos, asegurando así una paz estable y un bienestar como nunca habían existido hasta entonces en España; ahora bien, dejando bien claro su rechazo a la desideologización que preconizaban los partidarios del desarrollismo europeo. Desideologización y desarrollismo, reciben un varapalo evidente en las páginas del Suplemento, con puyas a los tecnócratas o minusvalorando el Plan de Estabilización y el turismo -considerados como dos males menores-, mientras se niegan fenómenos problemáticos, tan evidentes en aquel momento, como la emigración o el éxodo rural.

\section{Una aproximación comparativa}

El Arriba no fue el único medio que editó un suplemento especial por el inicio de los XXV años de Paz, ni tan siquiera mantuvo esa exclusividad dentro de la Prensa del Movimiento. Casi todos los periódicos sacaron en abril de 1964 números monográficos o especiales ${ }^{17}$. Lo ideal habría sido analizar pormenorizadamente cada uno de ellos, pero nos limitaremos a una comparación mínima de aspectos básicos para encuadrar este Suplemento dentro de la estructura periodística española y su relación con las restantes publicaciones y con los organismos oficiales dedicados a la prensa. Del alto número de cabeceras existentes, hemos optado por las de mayor tirada y difusión territorial, así como por la elección del caso de Asturias, como ejemplo territorial extrapolable y paradigmático dada la multiplicidad y calidad de sus periódicos y de sus profesionales.

\subsection{Suplementos y Especiales de los principales periódicos: semejanzas y diferencias}

El vespertino Pueblo, dirigido por Emilio Romero y recién aposentado en su sede de la calle Huertas (Naseiro, 2013: 12-18), lideraba los números de tiraje de toda la prensa pública española, aunque lejos de los de La Vanguardia y del ABC. Para la ocasión del 1

\footnotetext{
${ }^{17}$ Hasta Familia Española, órgano mensual de la Secretaría Permanente de los Congresos de la Familia Española, dirigida por Gabriel Elorriaga editó un número especial: "XXV años de Paz para la Familia Española".
} 
de abril (Hemeroteca Municipal de Madrid, 332-354/1), elaboró un Extra que iba inserto en las páginas centrales, ocupando cuarenta y dos páginas, la mitad del total, "divididas en dos cuadernillos de 24 y 16 respectivamente [más portada y contraportada], que el lector deberá reclamar, y su precio es de TRES PESETAS en lugar del corriente de dos", tal y como rezaba en la primera plana. Arrancaba con una foto oficial de Franco, también vestido de civil, junto al vanguardista cartel anunciador de los XXV años, la obra emblemática de Julián Santamaría López (Gil, 2007: 302), aunque la importancia que se dio a las imágenes, al diseño y a la publicidad fue mucho menor que la que hemos visto en el Suplemento.

Igualmente, de las diecisiete colaboraciones relacionadas con el evento y exceptuando las declaraciones de Franco al director de $A B C$, Torcuato Luca de Tena, sólo dos de ellas aparecen firmadas ${ }^{18}$. Resulta chocante tanto que el artículo estrella procediera de otro medio, como la ausencia de firmas en un rotativo que contaba con algunos de los mejores periodistas de la época ${ }^{19}$. Una ausencia que se hace extensiva al mismo Romero que tampoco rubrica los dos escritos que componen un único editorial: "No éramos un peligro para la paz", sobre el aislamiento internacional, y "Un proceso evolutivo", que versa sobre la historia y el peso de la Organización Sindical Española (OSE), propietaria del periódico. Son artículos que, en su mayoría, readaptan la información oficial en torno a la sanidad, los seguros sociales, la economía, los sindicatos -el tema más representado-, la enseñanza, la formación profesional, el turismo, la promoción de la mujer, la televisión, el panorama del fútbol, la vida cultural y literaria. Muestra evidente del desdén de Romero hacia la campaña de los XXV años y lo que representaba, aunque sin caer nunca en el desacato, con esa habilidad tan característica del Gallo de Arévalo.

El $A B C$ sí que realizó un gran esfuerzo para elaborar un número conmemorativo especial ofrecido conjuntamente con el diario ${ }^{20}$. Sin duda, la propuesta más ambiciosa y más lograda de toda la prensa española en torno a este hecho; esfuerzo generosamente correspondido con la concesión en exclusiva de una de las contadísimas entrevistas públicas ${ }^{21}$ que mantuvo Franco como Jefe de Estado. La publicación del extraordinario conmemorativo se dividió en dos entregas: el 31 de marzo de 1964 salía el "I Número conmemorativo. Del gorro frigio a la hoz y el

\footnotetext{
18 "Visión militar del Ejército de Franco", por el general José Díaz de Villegas, que también escribe en La Vanguardia y en el Ya, y “La motorización, símbolo del nivel de vida español”, por J. M. Quiroga.

${ }^{19}$ Rafael Marichalar, Miguel Ors o José María García en deportes, Funes Robert en economía, Máximo como ilustrador, Paco Cercadillo y Bullón en toros, Enrique Rubio en sucesos.

${ }^{20}$ http://hemeroteca.abc.es/nav/Navigate.exe/hemeroteca/madrid/abc/1964/04/01. Consultado el 23 de marzo de 2017.

${ }^{21}$ Después de ésta, sólo hay constancia de dos entrevistas; la última, con José María Bárcenas de interlocutor (4 de julio 1974), saldría póstumamente en el Blanco y Negro en 1976, mientras que la que concedió a Blanco Tobío y el Arriba en el 30 aniversario del final de la Guerra (1 de abril de 1969), se reprodujo en toda la prensa española.
} 
martillo", y el 1 de abril el "Il Número conmemorativo. Veinticinco años de Paz". Dejando a un lado el primero de los números y su inequívoca pretensión histórica condenatoria, nos centraremos en el segundo, y en sus cuidadas sesenta páginas, con catorce de ellas dedicadas enteramente a la publicidad. Llevaba como portada el retrato oficial de Franco de 1962, con uniforme del Ejército y se abría con un escrito del director -"Antes y después de la 'cota cero'"-, toda una loa a la actuación de Franco en su doble vertiente como militar y como gobernante.

Los diferentes artículos, a diferencia de lo que sucede en el Suplemento del Arriba, estaban agrupados ordenadamente, en tres secciones temáticas: I.-"La Administración", conformada mediante dos síntesis sobre los distintos gobiernos de Franco desde los tiempos de las Juntas de Defensa Nacional y Técnica del Estado hasta el presente; II.-"El Exterior", siguiendo idéntico esquema cronológico pero aplicado a la política exterior española, desde la etapa del aislamiento a la integración en los organismos internacionales; y III.-"Las realizaciones", el apartado al que se prestaba la mayor importancia tanto por el número de entradas -siete- como por el peso -y la juventud- de los autores, todos ellos en la órbita de Carrero. Esta tercera sección se subdividía a su vez en tres ámbitos: a) "Industrialización”, encabezado por un artículo de Gonzalo Fernández de la Mora, crítico cultural del $A B C$ y referencia intelectual del conservadurismo 22 (González Cuevas, 2007: 11-65) -"Loa al hombre de empresa"-, seguido de tres contribuciones menores; b) "Estabilización", a cargo en su totalidad del ministro de Hacienda, Mariano Navarro Rubio -"Ante un esperanzador porvenir económico"-, blanco de muchas de las contribuciones del Suplemento, como ya se ha apuntado; y c) "Desarrollo", encomendado a dos destacados tecnócratas, Laureano López Rodó, comisario del Plan de Desarrollo - "El desarrollo económico, instrumento de solidaridad"-, y José Luis Mora Mallo -"Mayor nivel de vida"- que con tan solo veintisiete años de edad y ya brillante economista del Banco Exterior de España, dio a la prensa un artículo de fondo pleno de datos estadísticos y en el que no se hacía referencia alguna ni al Movimiento ni a los Sindicatos Verticales. Cerraban el especial dos páginas con la famosa, y tantas veces citada, declaración de Franco.

La Vanguardia Española, dirigida por Javier Echarri Gamundi planificó también su contribución al arranque de los XXV años de Paz con varias entregas editoriales. Junto al número del 1 de abril, se lanzó un Especial ${ }^{23}$, mientras en el número ordinario se daba cabida a bastantes entradas sobre la efeméride ${ }^{24}$, anunciándose, también, un

\footnotetext{
${ }^{22} \mathrm{Al}$ año siguiente, sacaría en Rialp la obra que tanta repulsa causó entre la intelectualidad "azul”, El crepúsculo de las ideologías.

${ }^{23}$ http://hemeroteca.lavanguardia.com/edition.html?edition=Ed. + General\& $x=18 \& y=14 \& b d=01 \& b m=04$ \&by=1964. Consultado el 5 de febrero de 2017.

${ }^{24}$ El titular era "XXV años de Paz y de Trabajo". Franco aparecía en su biblioteca retratado por Campúa; en la página 6, el tradicionalista José Rico de Estasen firmaba un convencional "Veinticinco años de Paz en España", seguido en la 7 por "Una honda y vital reconstrucción" y la columna de Tomás Salvador, colaborador asiduo de La Vanguardia, titulada para la ocasión "El libro de la vida y de la paz". En la
} 
Extraordinario para el 1 de mayo. El Especial propiamente dicho, constaba de 64 páginas -28 de ellas de publicidad- con una portada del matrimonio Franco en el puerto de Barcelona, compartida con el icónico cartel de Santamaría, y el editorial "Nuestros primeros veinticinco años de Paz". Los veintidós trabajos integrantes son, como sucede en el Arriba, muy variopintos en cuanto a profundidad de tratamiento o alcance territorial, puesto que se incluyen tres artículos de temática catalana.

Aunque predomina la información sobre los éxitos económicos e industriales en la línea desarrollista clásica, el segundo ámbito lo copó la especialidad informativa de La Vanguardia (Davara, 2005: 138): la política exterior española y la visión de España en el extranjero. Seguía la lista temática Información y Turismo, cerrando la Agricultura y, por último, el Movimiento. Las tres firmas más prestigiosas presentes en el Especial no procedían de la abultada plantilla de La Vanguardia: José María de Areilza, embajador entonces en París, escribió "Hitos señeros de las batallas de la Paz"; Manuel Aznar, embajador ante las Naciones Unidas y exdirector de La Vanguardia hasta 1963, "Perspectiva exterior para las nuevas generaciones españolas", y el ministro de Hacienda, Navarro Rubio, "Síntesis en los progresos alcanzados gracias a veinticinco años de una paz fecunda". Junto a estos nombres destacados, fueron entrevistadas los ministros Martínez Sánchez-Arjona -Vivienda-, López-Bravo -Industria- y Fraga Información y Turismo-; las dos terceras partes de los artículos informativos iban sin firmar o sólo con iniciales ${ }^{25}$, y en cuanto a los autores de la casa que emplean sus nombres, se dedican a reportajes locales ${ }^{26}$.

La Editorial Católica, propietaria del Ya, dirigido por Aquilino Morcillo Herrera planificó cuidadosamente un Especial para el 1 de abril (Hemeroteca Municipal de Madrid E: 2037, T.2). La forma utilizada seguía en todo la de sus Dominicales. También se confería una gran importancia a la publicidad y a la modernidad compositiva. Constaba de 46 páginas, con la portada -en color, al igual que la contra- ocupada enteramente por una foto familiar de Franco, obra de Martín Santos Yubero "obtenida expresamente para este número"; la imagen simbólica, cercana y paternal, coincidía con la propuesta en la campaña de los XXV años.

Cinco ministros abrían el Especial con sus contribuciones, en lo que fue la mayor participación ministerial en toda la prensa y una muestra de la cercanía al sector católico del gobierno; figuraron Lora Tamayo -"Elevación del nivel cultural medio del Español”-; Jorge Vigón -“Una tercera parte de las inversiones públicas del Plan de

página 8, aparecían "Cinco lustros de trabajo en orden" y dos artículos especializados, uno sobre las enseñanzas militares de la contienda -por el capitán de Ingenieros Francisco López de Sepúlveda- y otro sobre la evolución naviera española -por Juan B. Robert-.

25 "F.A.G." -Federico Abascal Gasset- y "F.G.S." -Francisco Gor-, entonces dos jóvenes periodistas, que acabarían triunfando profesionalmente en la Transición.

${ }^{26}$ Tomás Rabanal Brito escribiendo sobre Extremadura y Juan Potau Compte sobre Tarragona. 
Desarrollo, para obras públicas"-; Navarro Rubio -"Claro optimismo en el futuro de nuestras relaciones financieras"-; Martínez Sánchez-Arjona -"Más de un millón de nuevas viviendas gracias a la protección oficial"-; y Cirilo Cánovas, el titular de Agricultura -"Necesidad de abrir vías a la comercialización de los productos agrícolas y ganaderos"-. Tras este golpe de efecto, venía una página sinóptica de datos -“Cifras de veinticinco años"-, seguida por la interpretación canónica de la Guerra defendida por el general Díaz de Villegas - "Desarrollo sintético de la guerra de Liberación”- (Díaz de Villegas, 1964: 25-29 y Martínez-Vasseur, 2011). Las restantes contribuciones pertenecían a reconocidas personalidades católicas, como eran el doctor Carlos Jiménez Díaz - "Nuestra medicina está al nivel de la de cualquier otro país"- y el jurista Luis Sánchez Agesta que, en su artículo "La Victoria y la Paz", defiende la superación del enfrentamiento entre las dos Españas, la integración de los vencidos y la concordia -que no "reconciliación"27-, como elemento constructivo social superador: "el vencido no sea un enemigo, sino un posible colaborador [...] otros veinticinco años de paz, fundándola sobre la concordia". Entre los periodistas del Ya que intervinieron están Fernando Martín-Sánchez Juliá, uno de los primeros integrantes de la Asociación Nacional de Católicos Propagandistas y director de la antigua escuela de El Debate (Cantavella, 2003: 81-85), autor de las entradas referentes a la agricultura, y dos jóvenes, también muy cercanos a la ANCP: Enrique Domínguez Millán y Manuel Alcántara, el poeta malagueño que fuera también colaborador habitual del Arriba y que en esta ocasión forma frente común con Sánchez Agesta en la defensa de la concordia y en la superación del guerracivilismo, dos ideas subyacentes a su artículo "Juegos en Paz", en el que se cita como autoridades a Antonio Machado y a Bertrand Russell, "un gran pacifista, no siempre bien entendido".

\subsection{Un ejemplo regional: la prensa en Asturias el 1 de abril de 1964}

La Asturias de 1964 encabezaba la España industrializada y urbanizada, con sus poco más de 985.000 habitantes, la mitad localizados en núcleos urbanos, con un 39\% de la población dedicado a la minería y la siderurgia y con tres de las diez empresas más grandes del país -ENSIDESA, UNINSA y HUNOSA- radicadas en su territorio. La quinta provincia española por su renta per cápita había experimentado, dos años antes, una huelga general que preocupó seriamente al Régimen (Cañada, 1978: 9, 55, 155 y 169). En correspondencia con todos estos datos, el número de periódicos -y de lectores- era de los más altos en términos relativos, pero también absolutos, porque disponía de

\footnotetext{
${ }^{27}$ El término "reconciliación" fue el que propuso como lema el Comité Central del PCE a partir de 1956 en su afán por crear un frente nacional antifranquista, por lo cual quedó prácticamente proscrito, aunque se había usado con anterioridad por parte de destacados elementos del franquismo como Yagüe en 1938 (Valiente, 2012: 80) o Serrano Suñer en 1947 (Serrano Suñer, 1977: 102).
} 
cinco diarios (Cabal, 2019 y Fernández Abello, 1976: 211), mientras que en Madrid llegaban a ocho en total, sumando dos periódicos deportivos. Ésta era una peculiaridad atípica sólo compartida en la zona noroeste con La Coruña y sus cuatro diarios. Otra característica propia, proviene de la superioridad de los medios privados -tres-, frente a los de la cadena de Prensa del Movimiento -dos-, aunque luego las tiradas correspondientes matizasen bastante la diferencia de partida. Tal auge periodístico, aún dentro de su modestia material y limitada proyección, daría lugar a una cantera de profesionales de alto nivel, de la que saldrán algunas de las firmas y voces más reconocidas de la Transición.

Puede afirmarse que la prensa asturiana representa fidedignamente a la restante prensa española de provincias en el tratamiento dado a los XXV años de Paz (Langa, 1998: 79-128). Asume la intención última del equipo interministerial comandado por Fraga en su pretensión por llegar hasta el último rincón de España, en un afán propagandístico totalizador sin precedentes; también recoge las líneas ideológicas generales que resultaban ser prácticamente las mismas en todas partes, pero la distancia física con respecto a los centros de poder $\mathrm{y}$ un asumido incipiente regionalismo moderado, permitieron ciertas libertades temáticas y unas singularidades interpretativas propias, aunque siempre en dosis mínimas.

Voluntad fue la cabecera del Movimiento en Gijón desde 1937 y el diario con menos tirada y recursos económicos de todos en 1964. Dirigido por Federico Miraz Fernández seguía editándose con la anticuada maquinaria de La Prensa, convertido en un periódico exclusivamente local. Incapaz de competir con El Comercio, el otro órgano gijonés, languidecía asistido únicamente por la inyección económica de la cadena estatal. El 1 de abril ${ }^{28}$ salió a la calle al inusual precio de 6 pesetas, por la consabida adición obligatoria del Suplemento. Su contribución propia se limitó, sin embargo, a tan solo seis páginas extraordinarias ${ }^{29}$, añadidas a las doce habituales, con anodinos reportajes sobre aspectos locales de Gijón. Todos estos artículos van sin firma, al igual que la tópica columna de entrada -"Veinticinco años de vida asturiana"- que acompaña el cartel oficial de Julián Santamaría. Hay una única excepción y es la incendiaria y fuera de lugar columna de Vallina ${ }^{30}$ _iVivan las cadenas!”-, un feroz ataque encubierto contra los tecnócratas y aperturistas que finalizaba con esta frase amenazadora: " $Y$

28 https://hemeroteca.gijon.es/detalle.html?info=https://fondos.gijon.es//fotoweb/archives/5000Hemeroteca/Hemeroteca/Voluntad/196404. Consultado el 27 de junio de 2018.

${ }^{29}$ En las doce páginas iniciales había un editorial sobre el tema -“Veinticinco primeros de abril”- y cuatro entradas alusivas informando del indulto con motivo de los XXV años, la entrega de condecoraciones, el deporte en el último cuarto de siglo y el Te Deum rezado en la iglesia de San Pedro.

${ }^{30}$ Seudónimo, quizás, de Salvador Vallina López: falangista fundador del SEU, colaborador del Arriba, oscuro espía que tuvo una actuación destacada en el regreso a España del excomunista Enrique Castro Delgado. 
ahora que me llamen demócrata, fascista o rojo. Lo único que sé es que no me gusta un pelo el despotismo ilustrado o sin ilustrar".

En cambio, el otro diario del Movimiento en Asturias, La Nueva España de Oviedo (Biblioteca de Asturias "Ramón Pérez de Ayala", Ast. PP2), sobresalía por encima de los demás en difusión y en calidad. Buena parte de su éxito lo debía a la duradera dirección de Francisco Arias de Velasco, lo que no impidió que éste fuera cesado abruptamente en octubre de aquel mismo año por un encontronazo con el gobernador civil, Mateu de Ros. Aparte del obligado Suplemento nacional, el número de La Nueva España del 1 de abril incorporó un magnífico Extraordinario de 32 páginas; una edición equiparable a la de los más grandes rotativos en cuanto a la exhaustividad temática y a la calidad formal de los reportajes que compusieron un informe sociológico completo y sin el lastre del triunfalismo imperante.

Este fondo común, regionalista y partidario del periodismo de investigación y de la información ecuánime, constituirá el germen de la posterior revista Asturias Semanal ${ }^{31}$ (Ruitiña, 2012) fundada en 1969 por uno de los redactores más activos del Extraordinario, Graciano García García (Lillo, 2012). Los artículos del Extraordinario abarcaban a casi todos los sectores económicos y sociales de la provincia, además de las inevitables referencias a la labor social del Movimiento y de los otros poderes públicos, y hasta con una entrada sobre la gastronomía asturiana. Tengamos en cuenta que la media de edad de los diez periodistas que compusieron el Extraordinario, estaba en 33 años y cuatro de ellos ni siquiera llegaban a los 25; todos se habían formado ya en la Escuela Oficial de Periodismo -excepto el más veterano, Juan Luis Cabal Valero- y tres procedían de familias relacionadas con la profesión periodística Juan Luis Cabal, Manuel Fernández Avello y José Antonio Cepeda-. Fue un conjunto de nombres con una proyección posterior exitosa en el mundo de la comunicación, tanto en Asturias $^{32}$ como fuera ${ }^{33}$. Algunos, incluso, llegaron a alcanzar una notoriedad manifiesta, como Graciano García, promotor de los Premios Princesa de Asturias y José

\footnotetext{
${ }^{31}$ En Asturias Semanal intervendrían otros compañeros del Extraordinario de La Nueva España -Lillo, Arce...- junto a nombres que acabarían siendo referentes en el periodismo posterior como Juan Cueto y Lalo Azcona. De este proyecto saldrían también el diario Asturias diario regional, aparecido en 1978 y, posteriormente, los míticos Cuadernos del Norte (1980), bajo la dirección de Juan Cueto Alas.

${ }^{32}$ Juan Luis Cabal Valero llegó a ser director de La Hoja del Lunes y redactor jefe de La Nueva España, Manuel Fernández Avello ocupó el cargo de cronista oficial de Oviedo, siendo un elemento fundamental en la vida cultural asturiana, al igual que Juan de Lillo -posterior director de Región- y Evaristo Arce redactor jefe de Los Cuadernos del Norte-. José Antonio Cepeda González -Juan de Neguri- protegido de Sabino Alonso Fueyo, fue jefe de prensa y comunicación de la Diputación Provincial y de la empresa HUNOSA, y durante un tiempo dirigió Región. Aquilino Iglesias-Cuesta, especializado en información deportiva, corresponsal de Marca.

${ }^{33}$ Juan Ríos Suárez vinculado a la prensa del Movimiento hasta su extinción -redactor de La Voz de Castilla, subdirector de La Hora Leonesa-; Eugenio Martínez Pérez - Eugenio de Rioja- dirigió Línea de Murcia en 1969, regresando después como redactor a La Nueva España.
} 
Manuel Diego Carcedo, un renombrado corresponsal y referente televisivo casi hasta hoy mismo.

Región, el matutino ovetense, propiedad de Editorial Gráfica Asturiana S.A. -grupo empresarial cercano a El Debate-, había sido fundado en 1923, vinculado al tradicionalismo católico. En 1960 estaba dirigido por Ricardo Vázquez-Prada Blanco que escribe el editorial del 1 de abril (Biblioteca de Asturias "Ramón Pérez de Ayala", Ast. PP2) -"Paz para todos"-. Su escrito es una muestra palmaria de la interpretación canónica que apoyaría la Iglesia española posconciliar, partidaria de la reconciliación y de la superación definitiva de la Guerra:

La paz ganada el 1 de abril de 1939, tras la dura, sangrienta y amarga batalla, pertenece por entero a todos los españoles sin distinción de clases ni de ideologías [...] Paz para todos los españoles, paz para todos los hogares, paz para todas las fábricas y talleres, para todas las minas y buques, para todas las aulas. Paz evangélica, paz del pan que salva y conforta, paz en el espíritu de los que combatieron, aquí o allá, por un limpio ideal.

Este Especial tenía sólo cuatro páginas. Destaca la presencia de los testimonios -"Tres españoles opinan sobre la paz"- en los que intervinieron dos conocidas personalidades: el maestro Joaquín Rodrigo y el escritor Miguel Mihura. Otra nota original fue la firma de un artículo por parte de una de las primeras mujeres periodistas surgidas en la década de los sesenta, María Teresa Dolset Romero, de la agencia Pyresa -"La familia, la gran protagonista de nuestra paz"-. Cerraba el número un artículo de José Antonio Cepeda -"Tres vertebrales obras de la paz asturianas" ${ }^{34}-$, al que también hemos visto simultáneamente actuar como redactor de La Nueva España.

La Voz de Asturias, creado también en 1923, en Oviedo, por el empresario Tartiere, pertenecía desde 1963 al grupo periodístico de El Faro de Vigo encabezado por Amado de Lema; su director, Jorge Víctor Sueiro (Cabal, 2019: 172-193), también provenía del ente gallego. La Voz tenía fama de ser un medio bastante crítico, habiendo cubierto con todo detalle, y sin temor a la censura, las grandes huelgas de 1962, lo que le convirtió en el periódico de las cuencas mineras. Sin embargo, nada de ese presunto izquierdismo opositor se encuentra en el Suplemento especial (Biblioteca de Asturias "Ramón Pérez de Ayala", Ast. PP2) del 1 de abril. Constaba de 10 páginas, cada una de las cuales recogía información institucional de lo más encomiástica y oficialista posible, toda ella sin firmar ${ }^{35}$, excepto la de la página $X$, autoría de Jaime Peñafiel para la

\footnotetext{
${ }^{34}$ Estaba extractado de su libro Asturias. España en Paz y formaba parte de la colección dedicada a cada una de las provincias españolas que editó Publicaciones Españolas en el marco de los XXV años de Paz.

${ }^{35} \mathrm{I}$ : artículo sobre los generales de la Victoria y artículo sobre la educación en España; II: sobre el ferrocarril vasco-asturiano y una entrevista a Cepeda, de nuevo sobre su libro Asturias. España en Paz; III: declaraciones del Gobernador Civil, José Manuel Mateu de Ros; IV: un balance de la actuación del alcalde de Oviedo, Antonio Rico de Eguíbar; V: sobre la Diputación; VI: sobre las realizaciones sociales;
} 
agencia Pyresa, poco antes de que el mediático periodista entrase en la plantilla de la revista $i$ Hola!. Se trataba de una entrevista, con pregunta única, al equipo ministerial "El 10 de abril de los ministros de hoy"-, siguiendo la misma fórmula empleada en el Suplemento del Arriba.

El Comercio, decano de los periódicos en activo en el Principado, seguía siendo un diario local y bastante independiente para los parámetros del momento, manteniendo la línea conservadora ilustrada característica de la casa. Desde 1954, Francisco Carantoña Dubert sería su sempiterno director hasta 1995. Carantoña optó por una solución original para cumplir con las consignas ministeriales ante el 1 de abril, pero sin alterar en exceso la dinámica habitual. Optó por no lanzar ningún Suplemento, sino que dedicó cinco de las doce páginas cotidianas al evento ${ }^{36}$. Igualmente, con su habilidad característica, buscó un equilibrio en las colaboraciones -todas externas a la redacción del periódico-; dio cabida a las interpretaciones y los puntos de vista más doctrinalmente ortodoxos para así poder "colar" otras más aperturistas, evitando la censura.

La portada, junto a un retrato de Franco y el cartel oficial en una de las calles de Gijón, acogía el editorial del director, "Meditación de la paz", en el que se hacía una soterrada defensa de la superación definitiva de la Guerra y una propuesta de progreso en todos los órdenes para España. En la página 3, iba un artículo del ministro del Ejército referido a aspectos histórico-militares del bando nacional junto a otro de Isidoro Martín Martínez, catedrático de derecho, miembro destacado de la ACNP y salido de las filas de El Debate -“Colaboración amistosa entre la Iglesia y el Estado Español en estos veinticinco años de paz"- donde se hacía una defensa del Concordato de 1953 en particular y de la apertura de España al mundo en general. La página siguiente se abría con un incendiario artículo de Blas Piñar -“Conmemoramos veinticinco años de paz, pero también de una victoria que ha de mantener cada día su vigencia"-, inmerso de pleno en su deriva extremista desde que escribiera públicamente ("Hipócritas", $A B C, 19$ de enero de 1962) contra los pactos con los Estados Unidos; junto a él aparecía Pedro Gómez Aparicio -“España ya conoce qué es la paz"-, representante por excelencia del adoctrinamiento informativo a favor del Régimen y, todavía, con un gran peso en la profesión. En la misma órbita iban las contribuciones del militar africanista Tomás García Figuera y del periodista asturiano del Ya, Antonio José González Muñiz. Junto a todo esto, Luis Sánchez Agesta -"Saldo favorable de 25 años de paz"-, defendía una propuesta católica integradora: "las diferencias ideológicas sobre problemas de la vida política española no son hoy inconciliables".

VII: "25 años de política exterior española"; VIII: sobre la Sanidad; IX: sobre la circulación y el parque automovilístico.

${ }^{36}$ https://www.elcomercio.es/hemeroteca/19640401. Consultado el 12 de marzo de 2018. 
El cierre se encomendó a un polémico Claudio Fernández Junquera -“Los que ganaron la Paz"-, identificado con los posicionamientos de Carantoña y de Sánchez Agesta. Su artículo conciliador defendía un futuro "distinto" y representaba el anhelo de una nueva generación aperturista, lo que no dejaba de ser toda una provocación dado que, además, Fernández Junquera era hijo de un ilustre fusilado por los rojos.

\section{Conclusiones}

El análisis del Suplemento del Arriba no añade nada a lo que ya sabemos sobre el acontecer de esta campaña propagandística, pero abre dos vías temáticas distintas para su correcta interpretación (Eiroa, 2014: 253-264). La primera es su contribución como fuente complementaria (Hernández Ramos, 2017: 465-477) al explicar las interrelaciones establecidas entre el hecho en sí, la sociedad y las diversas estructuras de poder en ese momento crucial de 1964 y, también, cómo las diferentes ideologías del Régimen convirtieron los XXV años de Paz en un auténtico símbolo emocional, sujeto a sus propias interpretaciones múltiples. Por otra parte, como fuente directa, nos ayuda a aclarar el panorama de la situación periodística española en general y la de la Prensa del Movimiento en particular, al poner de manifiesto muchos de sus condicionantes, tanto los inmediatos -la presión ministerial, la acogida de los lectores, la actuación de los directivos y demás profesionales...-, como los de más largo plazo -la propiedad y situación económica de los medios, el marco legislativo, el cambio generacional de los periodistas...-.

Fuera de la clandestinidad, resultaba casi impensable oponerse a la celebración según la concibieron y desarrollaron Fraga y su equipo. Sin embargo, no se logró que hubiera una completa unanimidad ante los fastos gubernamentales. Los medios de comunicación, a su modo, reflejan el distinto grado de identificación social y de identificación grupal que mantuvieron cada una de las familias que componían el Franquismo, en una escala que iba desde la entusiasta identificación hasta el distanciamiento desdeñoso, pasando por una neutralidad con matices. En 1964, dos años antes de la famosa Ley de Prensa, ya existía en la práctica una tímida protopluralidad informativa (Vela, 2009: pp.620-627 y Míguez, 1990), a la que luego la Ley daría carta de naturaleza reduciendo el control ministerial y ampliando la autonomía de gestión y la libertad de información y de opinión, con las consabidas restricciones y excepcionalidades (Greciet, 1998). El ministro de Información y Turismo, junto a Solís $y$, en ocasiones, al almirante Nieto, encarnaba una línea de apertura institucional, basada en la "política de realizaciones" y en el "ejercicio correcto y oportuno del poder", que era considerada por parte del sector más "azul", el identificado con el Arriba, toda una traición a las esencias del 18 de julio. Carrero 
Blanco junto a su equipo tecnocrático afín no mostraban tampoco excesivas simpatías hacia ese "laborismo a la española" de Solís. Pero los desarrollistas dejarán a un lado sus escrúpulos y rencillas personales para apoyar la campaña de los XXV Años de Paz en aquello que coincidía plenamente con sus objetivos: la despolitización inhibidora, la transmutación de la imagen de Franco en un De Gaulle paternalista y la utilización de la celebración como formidable escaparate expositivo de los avances conseguidos y un anuncio a gran escala de los futuros Planes de Desarrollo (Torre, 2009: 61-88). La crisis de gobierno de 1969, acabaría cercenando este tímido y contradictorio aperturismo que, en 1964, había disfrutado de uno de sus mayores momentos de gloria gracias, sin duda, al éxito de los XXV años de Paz Española (Hispán, 2006).

Toda esta ebullición histórica, propia de una coyuntura de crisis, trasciende también al periodismo de entonces inmerso en su propia catarsis. Además de las discrepancias ideológicas encubiertas, asistimos a un enfrentamiento de fondo entre dos formas opuestas de entender la profesión. Las nuevas generaciones de periodistas surgidas después de la Guerra -y cada vez más ajenas a ella-, defienden unos principios éticos y unas maneras formales que chocan con aquellos otros que siguen aún aferrados a un periodismo de combate y adoctrinamiento, aunque vaya disfrazado con los últimos avances tecnológicos o con la retórica de una supuesta superioridad moral. Las antiguas fórmulas de propaganda se mostraban incapaces de competir ante el empuje de las técnicas de marketing y publicidad y el atractivo estético del nuevo diseño, los dos grandes principios que sustentan toda la estructura informativa de los XXV años. EI Suplemento del Arriba constituye así la mejor muestra de ese viejo periodismo abocado a una decadencia sin remedio (Martínez Fábregas y Romero-Domínguez, 2014: 321-340), a pesar de la indudable calidad individual de muchos de sus integrantes y de todos los intentos formales de puesta al día que se hicieron.

De igual modo, los suplementos y extras del $A B C$, La Vanguardia, el $Y a$ y de algunos otros medios regionales y locales o bien apuntan, o bien ya ejercitan plenamente este nuevo periodismo español que marcará las dos décadas siguientes, aunque aún permanezcan en sus páginas muchos redactores -y resabios- propios del pasado. De este modo, no debiera resultarnos tan paradójico el que la mayoría de los periodistas que cubrieron la Transición y contribuyeron, en buena medida, a hacerla posible, salieran, como hemos visto, de los periódicos provinciales de entes privados o incluso de las cabeceras de la Prensa del Movimiento (Martín de la Guardia, 1994) o de Pueblo (Alférez, 1986). Los directores de los medios estatales ya anteponían la preparación y la calidad de los redactores y colaboradores a los certificados de adhesión; así, Emilio Romero no resultaría ser una extraña excepción sino la confirmación de esta nueva norma no escrita. Por otra parte, las columnas de la prensa oficial suponían un cauce de estreno laboral asequible a las nutridas promociones de la Escuela de Periodismo, poco escrupulosas en lo referente a la titularidad de los medios o a sus estrechos vínculos con el Régimen (Barrera, 1991: 173-180). Al fin y al cabo, hicieron lo mismo 
que los numerosos artistas e intelectuales que contribuyeron con su obra y con su nombre a los XXV años de Paz de Fraga (Iglesias, 2012: 159 y ss.); como muchos de ellos, acabarían finalmente engrosando las filas de la oposición a la Dictadura durante el tardofranquismo.

\section{Bibliografía y fuentes}

ABAD, C., GARCÍA, J.L. y MUÑOZ, C. (1994): "La agricultura española en el último tercio del siglo XX: principales pautas evolutivas", en SUMPSI, J.M.: Modernización y cambio estructural en la agricultura española, Madrid, Ministerio de Agricultura, Pesca y Alimentación, pp.69-125.

AGUADO, G. (1996): OJD y el control de la difusión de prensa en España, Barcelona, Ariel Comunicación.

AGUILAR, P. (2008): Políticas de la memoria y memorias de la política. El caso español en perspectiva comparada, Madrid, Alianza Editorial.

ALCALDE, A. (2014): Los excombatientes franquistas, 1936-1965, Zaragoza, Prensas de la Universidad de Zaragoza.

ALCOBENDAS, Ma.P. (2006): IOP. Historia del Instituto de la Opinión Pública 1963-1977, Madrid, CIS.

ALFÉREZ, A. (1986): Cuarto poder en España: la prensa española desde la ley Fraga 1966. Barcelona, Plaza y Janés.

AMAYA, A. (2008): "La figura de Franco en el discurso de la Organización Social Española durante los años del 'desarrollismo' a través del diario 'Pueblo' (19571969)", en Hispania, Vol. 68, no 229, 2008, pp. 503-531.

- (2010): El Acelerón sindicalista: discurso social, imagen y realidad del aparato de propaganda de la organización sindical española, 1957-1969, Tesis Doctoral, Barcelona, Universidad Autónoma de Barcelona.

AMILIBIA, J.M. (2005): El gallo del Franquismo, Madrid, Temas de Hoy.

BANCO MUNDIAL (1962): El desarrollo económico de España, Madrid, Oficina de Coordinación y Programación Económica de Presidencia del Gobierno.

BARRERA, C. (1991): “Caracterización regional de la Prensa del Movimiento", en DELGADO, J.M. y MARTíNEZ LATRE, M.P. (eds.): Jornadas sobre prensa y sociedad, Logroño, Instituto de Estudios Riojanos, pp.173-180. 
- (1995): Periodismo y franquismo. De la censura a la apertura, Barcelona, Ediciones Internacionales Universitarias, 1995.

BELTRÁN, M. (1994): Política y administración bajo el franquismo: la reforma administrativa y los planes de desarrollo, Madrid, Instituto Juan March, 1994.

BENEYTO, J. (1965): "Los diarios impresos españoles", en Revista Española de la Opinión Pública, № 1, 1965, pp.9-26.

- (1986): "Los Consejos de Prensa bajo el franquismo", Revista de Estudios Políticos, no 52, julio-agosto, 1986, pp.217-242.

Boletín del depósito legal de obras impresas (1963), Madrid, Dirección General del Archivos y Bibliotecas, no 58.

BIBLIOTECA DE ASTURIAS “RAMÓN PÉREZ DE AYALA”: Ast PP2 -microfichas-.

BIBLIOTECA NACIONAL: HNC/62.

BOVES, C. (2014): Teodoro Delgado: Forja de lápiz y pincel, Madrid, Create Space Independent Publishing Platform.

BURGUERA, M.L. (2012): “La Oración por los caídos, de Rafael Sánchez Mazas: el discurso fúnebre y la retórica política", en RíO, E., RUIZ DE LA CIERVA, M.C. y ALBADALEJO, T. (coords.): Retórica y política: los discursos de la construcción de la sociedad, La Rioja, Instituto de Estudios Riojanos, pp.519-532.

BUSTAMANTE, E. (2013): Historia de la Radio y la Televisión en España. Una asignatura pendiente de la democracia, Barcelona, Gedisa.

CABAL, R. (2019): "Historia, memoria y otros antagonismos del periodismo asturiano contemporáneo: La Voz de Asturias (1962-1986)", en CABAL, R., FRISON, H. y GARCÍA, M. (coords.): Au-delà de la dualité: repenser les antagonismes de I'Espagne contemporaine (XIX-XXIe siècles) (2019), París, Universidad de la Sorbona 3, pp.172-193.

CABAÑAS, M. (coord.) (2003): El arte español fuera de España, Madrid, CSIC.

CANDELA, J. (2017): La política falangista y la creación de una cultura de propiedad de la vivienda en el primer franquismo, 1939-1959, Valencia, Universidad de Valencia (tesis doctoral).

CANTAVELLA, J. (2003): "La Escuela de El Debate y el inicio de la enseñanza del periodismo en España", Aportes. Revista de Historia Contemporánea, Vol. 18, № 51, 2003, pp. 81-85.

CAÑADA, S. (dir.) (1978): Historia General de Asturias, T. XII, Gijón, Silverio Cañada. 
CAÑELLAS, A. (2009): “Los caminos de la apertura política (1962-1969)”, en Memoria y Civilización, no 12, 2009, pp.253-280.

CARREDANO, V. (1964): España hoy: viva la Paz, Madrid, Junta Interministerial para la Conmemoración del XXV aniversario de la Paz Española.

CASTRO, A. (2017): "Síntomas de cambio: sociedad y cultura en el semanario Triunfo en torno al año 1964", en CASTRO, A. y DÍAZ, J. (coords.) (2017): XXV años de paz franquista: sociedad y cultura en España en torno a 1964, Madrid, Ed. Sílex, pp.99-126.

CHULIÁ, E. (2001): El poder y la palabra. Prensa y poder político en las dictaduras. El régimen de Franco ante la Prensa y el periodismo, Madrid, Biblioteca NuevaUNED.

CONDE, L. (2014): “Los inicios profesionales de Máximo San Juan”, en BOBILLO F.J et al: Máximo: trazos de una trayectoria, Alcalá de Henares, Fundación General de la Universidad de Alcalá-Instituto Quevedo del Humor, pp.15-29.

CONEKIN, B. (2003): The Autobiography of a Nation: The 1951 Exhibition of Britain, Representing Britain in the Post-War World, Manchester, Manchester University Press.

CONTRERAS, I. (2016): "'El Concierto de la Paz' (1964): Three Commissions to Celebrate 25 Years of Francoism", en BUCH, E., CONTRERAS, I. y DENIZ, M. (eds.): Composing for the State: Music in Twentieth-Century Dictatorships, Abingdon, Routledge, pp.168-186.

DAVARA, F. J. (2005): “Los periódicos españoles en el tardo franquismo. Consecuencias de la nueva ley de prensa", en Revista Comunicación y hombre, no 1, 2005, pp.131-147.

DÍAZ, J. y URIBE, E. (2005): El Yugo y las Letras. Bibliografía de desde y sobre el nacionalsindicalismo, Madrid, Reconquista.

DÍAZ DEL CAMPO, R.V. (2017): "Nuevos relatos del Régimen: carteles para XXV años de paz", en CASTRO, A. y DÍAZ, J. (coords.): XXV años de paz franquista: sociedad y cultura en España en torno a 1964, Madrid, Ed. Sílex, pp. 205-226.

DÍAZ DE VILLEGAS, J. (1964): “Nuestra Cruzada no fue, jamás, una guerra civil”, en Guión, vol. 266, 1964, pp.25-29.

DIEGO, A. (2016): “La prensa y la dictadura franquista. De la censura al 'Parlamento de Papel"'. Disponible en Internet (04-04-2019): https://riuma.uma.es/xmlui/bitstream/handle/10630/11297. 
EIROA, M. (2014): "Historia y Periodismo: interrelaciones entre disciplinas", en Historia y Comunicación Social, vol. 19, 2014, pp. 253-264.

ELLWOOD, S.M. (1987): "Spanish Newsreels, 1945-1975: The Image of the Franco Regime", en Historical Journal of Film, Radio \& Television, vol. 7, nํ, 1987, pp.225-238.

- (2001): Historia de Falange España, Barcelona, Crítica.

EQUIZA, P. (2015): Juan Beneyto: organizador y teórico de los estudios de comunicación en España, Tesis doctoral, Madrid, Universidad Complutense.

ESTÉVEZ, M. A. (1977): “El nacimiento de la prensa azul”, en Historia 16, no 9, 1977, pp.21-28.

Es así. Periódico sindicalista español (1963-1964), no 1-5.

FERNÁNDEZ AVELLO, M. (1976): Historia del periodismo asturiano, Gijón, Ayalga Ediciones.

FERNÁNDEZ AREAL, M. (1971): La libertad de prensa en España (1938-1971), Madrid, Cuadernos para el Diálogo.

FERNÁNDEZ DE LA MORA, G. (1965): El crepúsculo de las ideologías, Madrid, Ed. Rialp.

FRAGA, M. (1980): Memoria breve de una vida pública, Barcelona, Planeta.

FUENTES QUINTANA, E. (dir.) (1963): El desarrollo económico de España. Juicio crítico del Informe del Banco Mundial, Madrid, Revista de Occidente.

FUENTES, J. F. y FERNÁNDEZ SEBASTIÁN, J. (1998): Historia del Periodismo español. Prensa, política y opinión en la España contemporánea, Madrid, Ed. Síntesis.

GARCÍA DE DUEÑAS, J. (2000): El Imperio Bronston, Madrid, Editorial del Imán.

GARCÍA DE TUÑÓN, J.M. (2003): José Antonio y los poetas, Madrid, Plataforma 2003.

GARCÍA GALINDO, J. A., GUTIÉRREZ LOZANO, J. F. y SÁNCHEZ ALARCÓN, M.I. (coords.) (2002): La comunicación social durante el franquismo, Málaga, Diputación Provincial de Málaga.

GARCÍA, J. (1980): Radiotelevisión y política cultural en el franquismo, Madrid, CSIC.

GIL, E. (2007): Pioneros del diseño gráfico en España, Barcelona, Gustavo Gili.

GIMÉNEZ, M.A. (2015): “El corpus ideológico del franquismo: principios originarios y elementos de renovación", en Estudios internacionales (Santiago), no 47(180), 2015, pp. 11-45. 
GIRÓN, J. (ed.) (1995): La luz domesticada: vida y obra de Nicolás Muller, Oviedo, Universidad de Oviedo.

GONZÁLEZ SEARA, L. (1968): Opinión pública y comunicación de masas, Barcelona, Ariel.

GRECIET, E. (1998): Censura tras la censura. Crónica personal de la transición periodística, Madrid, Fragua.

HEMEROTECA DIGITAL $A B C$.

HEMEROTECA DIGITAL EL COMERCIO.

HEMEROTECA DIGITAL LA VANGUARDIA.

HEMEROTECA MUNICIPAL DE GIJÓN: VOLUNTAD,

HEMEROTECA MUNICIPAL DE MADRID: 332-354/1; E:2037, T.2.

HERNÁNDEZ RAMOS, P. (2017): “Consideración teórica sobre la prensa como fuente historiográfica", en Historia y Comunicación Social, vol. 22.2, 2017, pp.465-477.

HERAS, C. (2000): La prensa del movimiento y su gestión publicitaria, Málaga, Spicum.

HISPÁN, P. (2006): La política en el régimen de Franco entre 1957 y 1969. Proyectos, conflictos y luchas por el poder, Madrid, Centro de Estudios Políticos y Constitucionales.

IGLESIAS, J. (2012): “Manuel Fraga, sociólogo. Una aproximación”, en FAES, no 36, 2012, pp.151-169.

INSTITUTO DE OPINIÓN PÚBLICA (1964): Estudio sobre los medios de comunicación de masas en España, Madrid, IOP.

LANGA, C. (1998): “De la guerra civil a los XXV años de paz. Prensa y opinión política en la Sevilla franquista (1936-1964)", en REIG, R. y RUIZ ACOSTA, M. J. (coords.): Sevilla y su prensa. Aproximación a la Historia del periodismo andaluz contemporáneo. (1898-1998). Sevilla, Universidad de Sevilla, pp. 79-127.

LILLO, J. (2012): Graciano García. Nada fue un sueño, Oviedo, KRK.

LÓPEZ GALLEGOS, M.S. (2003): “Aproximación al estudio de las publicaciones sindicales españolas desarrolladas durante el franquismo (1936-1975)", en Historia y Comunicación Social, no 8, 2003, pp.159-185.

LÓPEZ PINTOR, R. (1981): “El estado de la opinión pública española y la transición a la democracia", en REIS, no 13, enero-marzo, 1981, pp.7-47. 
MAINER, J.C. (1971): Falange y Literatura. Antología, Barcelona, Labor.

Madrid: el arte de los 60, Madrid, Consejería de Cultura y Turismo, 1990.

MÁRQUEZ, D. (1977): Círculos José Antonio, Bilbao, Ed. Albia.

MARTÍN DE LA GUARDIA, R.M. (1994): Información y propaganda en la prensa del Movimiento. Libertad de Valladolid, 1931-1979, Valladolid, Secretariado de Publicaciones de la Universidad.

MARTÍNEZ FÁBREGAS, J. y ROMERO-DOMÍNGUEZ, L. R. (2014): “'Arriba' durante la Transición española: el abandono de su función propagandística con respecto al Gobierno", en Historia y Comunicación Social, no 19, 2014, pp. 321-340.

MARTÍNEZ-VASSEUR, P. (2011): “Historia y transmisión de la memoria de los vencedores de la Guerra Civil en la revista militar Ejército (1940-1975)", en Amnis, no 2, 2011. (Consulta: 03-02-2018).

MÁXIMO (1964): España para usted, Madrid, Subsecretaría de Turismo, 1964.

MíGUEZ, S. (1990): La preparación de la transición a la democracia en España, Zaragoza, Universidad de Zaragoza.

MOLINERO, C. e YSÁS, P. (2005): La captación de las masas. Política social y propaganda en el régimen franquista, Madrid, Cátedra.

MORALES, G. (2007): Falangistas en la oposición, Madrid, Fundación José Antonio.

MORENO, R. y DEMARÍA, J.F. (2013): José Demaría Campúa. Viviendo entre fotos. Antología de un reportero y artista gráfico, Barcelona, Península.

MUELA, A. (2010): Estudio de la poesía de Federico Muelas, Cuenca, Diputación de Cuenca.

NASEIRO, A. (2013): “El archivo del diario 'Pueblo'. Un apunte para la historia de la prensa en España durante el franquismo y la transición democrática", en Documentación en las Ciencias de la Información, vol.36, 2013, pp.11-29.

NÉGRIER, E. (2003): Las políticas culturales en Francia y España. Una aproximación nacional y local comparada, Barcelona, Institut de Ciències Polítiques i Socials.

NÚÑEZ, M. (2006): Arte y Política en la España del desarrollismo (1962-1968), Madrid, CSIC.

PACHO, F. (2006): “Álvaro López Núñez, un patricio leonés del periodismo y la sociología", en Tierras de León, vol.44, no 122-123, 2006, pp.73-115. 
PANDO, M. P. (2009): Ruiz-Giménez y Cuadernos para el Diálogo. Historia de una vida y de una revista, Salamanca, editorial L.C. 2009.

PAREJA, M. (2013): El periódico Mediterráneo durante la transición española (19751982), Castellón de la Plana, Universidad Jaime I.

PAYNE, S.G. (1985): Falange. Historia del fascismo español, Madrid, Sarpe.

PÉREZ BELDA, E.A. y PÉREZ ALMAGRO M.C. (2016): “La arquitectura desplegable conmemora los XXV años de paz. 50 Aniversario del Pabellón de Emilio Pérez Piñero", en EGA: revista de expresión gráfica arquitectónica, 2016, pp. 146-155.

PIZARROSO, A. (1989): "Política informativa: información y propaganda (1939-1966)", en ÁlVAREZ JESÚS, T. (ed.): Historia de los medios de comunicación en España. Periodismo, imagen y publicidad (1900-1990). Barcelona, ed. Ariel, pp.231-249.

PORTELA, A. (1987): Salazarismo e artes plásticas, Lisboa, Instituto de cultura e língua portuguesa.

PUBLICACIONES ESPAÑOLAS (1964): España en Paz [serie de 53 títulos], Madrid, Publicaciones españolas.

REBOLLO, M.A. (1978): Lenguaje y política: introducción al vocabulario republicano y franquista (1931-1971), Valencia, Fernando Torres Editor.

ROBLES, C. (2011): Memoria de cuatro Españas. República, guerra, franquismo y democracia, Barcelona, Planeta.

- (dir.) (1964): El gobierno informa. Sociedad española. 25 aniversario de la paz española, vol. 2, Madrid, Editora Nacional.

RODRÍGUEZ JIMÉNEZ, J. L. (1994): Reaccionarios y golpistas: la extrema derecha en España: del tardofranquismo a la consolidación de la democracia, 1967-1982, Madrid, CSIC.

RUITIÑA, C. (2012): Asturias Semanal. El nacimiento de un periodismo democrático, Gijón, Zahorí ed.

RUIZ CARNICER, M.A. (2014): “Fascistas de izquierda en los años sesenta. La búsqueda de las bases populares para el proyecto de una izquierda nacional en la España de Franco", en Rúbrica Contemporánea, no 5, 2014, pp.71-87.

SÁNCHEZ RADA, J. (1996): Prensa, del movimiento al socialismo: 60 años de dirigismo informático, Madrid, Fragua.

SÁNCHEZ-BIOSCA, V. (2007): “Las culturas del tardofranquismo”, en Ayer, no 68, 2007, pp.89-110. 
- (2014): "EI NO-DO y la eficacia del nacionalismo banal", en MICHONNEAU, S. y NÚÑEZ-SEIXAS, X.M. (dirs.): Imaginarios y representaciones de España durante el franquismo, Madrid, Casa de Velázquez, pp.177-195.

SERRANO SUÑER, R. (1977): Entre el silencio y la propaganda, la Historia como fue. Memorias, Barcelona, Ed. Planeta.

SERVICIO INFORMATIVO ESPAÑOL (1964a): 25 años de paz vistos por 25 escritores españoles, Madrid, SIE.

- (1964b): Veinte escritores españoles hablan de... 25 años de paz, Madrid, SIE.

- (1964c): España. Estado de Derecho: réplica a un informe de la Comisión Internacional de Juristas, Madrid, Servicio Informativo Español.

- (1965): Informe sobre la conmemoración del XXV aniversario de la paz española, Madrid, SIE, 1965.

SEVILLANO, F. (1996): Dictadura, socialización y conciencia política. Persuasión ideológica y opinión en España bajo el franquismo (1939-1962), Tesis doctoral, Alicante, Universidad de Alicante.

- (1997): "La estructura de la prensa diaria en España durante el franquismo", en Investigaciones Históricas, no 17, 1997, pp.315-340.

SUPLEMENTO NACIONAL DE LA PRENSA DEL MOVIMIENTO (1964): España cumple sus 25 años de paz, Madrid, Prensa del Movimiento.

TAPIA, A. (2001): "Las primeras enseñanzas de documentación en periodismo", Documentación de las Ciencias de la Información, no 24, 2001, pp. 231-253.

TEMAS ESPAÑOLES (1961): XXV Años de paz, Madrid, Publicaciones Españolas.

TERRÓN, J. (1981): La prensa de España durante el Régimen de Franco. Un intento de análisis político, Madrid, Centro de Investigaciones Sociológicas.

TORRE, J. (2009): “¿Planificando a la francesa? El impacto exterior en el desarrollismo", en TORRE, J. y GARCÍA-ZÚÑIGA, M. (eds.): Entre el Mercado y el Estado. Los planes de desarrollo durante el franquismo, Pamplona, Universidad Pública de Navarra, pp. 61-88.

TOWNSON, N. (ed.) (2007): Spain transformed: the late Franco dictatorship, 19591975, Nueva York, Palgrave Macmillan.

VALIENTE, G. (2012): "La idea de reconciliación nacional durante la Guerra Civil española. Los discursos de Yagüe y Azaña de julio del 38", en Aportes. Revista de historia contemporánea, no 80, 2012, pp.73-96. 
VELA, D. (2009): “Años sesenta: Balbuceos de libertad de prensa”, en BERNARDO, J. et $\mathrm{AL}$, De Azorín a Umbral. Un siglo de periodismo literario español, A Coruña, Netbiblo, pp. 620-627.

VIVÓ, E. (2017): El ideal individual y colectivo falangista en la poesía de Agustín de Foxá, Valencia, Universidad de Valencia.

YANES, J. A. (1995): "La prensa como sujeto y objeto de investigación histórica", en SANTACREU, J. M. (coord.) (1995): Historia contemporánea y nuevas fuentes, Alicante, Universidad de Alicante, pp. 71-79.

YBARRA, I. (2013): Alfonso de Zunzunegui: la aventura de vivir, Madrid, Ed. de buena tinta.

ZABALZA, R. (1966): La prensa económica en España, Madrid, Anexos de la Revista Española de Documentación, Ministerio de Información y Turismo.

ZALBIDEA, B. (1996): Prensa del Movimiento en España: 1936-1983, Bilbao, Universidad del País Vasco.

- (2002): "Prensa del Movimiento y Prensa del Estado. Un modelo de dirigismo institucional”, en GARCÍA, A., GUTIÉRREZ, J. F. y SÁNCHEZ, M.I. (coords.): La comunicación social durante el franquismo, Málaga, Diputación Provincial de Málaga, pp. 557-570.

ZAMARREÑO, G. (2015): "Al fin, la Paz", en Movilizaciones de masas del franquismo. Un espectáculo al servicio de la imagen de Francisco Franco, Tesis doctoral, Málaga, Universidad de Málaga, pp. 313-334. 